Portland State University

PDXScholar

1979

\title{
An evaluation of a data-based sex education training program for mentally retarded adults
}

Patricia Ann Riley

Portland State University

Follow this and additional works at: https://pdxscholar.library.pdx.edu/open_access_etds

Part of the Education Commons, and the Psychiatric and Mental Health Commons Let us know how access to this document benefits you.

Recommended Citation

Riley, Patricia Ann, "An evaluation of a data-based sex education training program for mentally retarded adults" (1979). Dissertations and Theses. Paper 2894.

https://doi.org/10.15760/etd.2888

This Thesis is brought to you for free and open access. It has been accepted for inclusion in Dissertations and Theses by an authorized administrator of PDXScholar. Please contact us if we can make this document more accessible: pdxscholar@pdx.edu. 
AN ABSTRACT OF THE THESIS OF Patricia Ann Riley for the Master of Science in Education presented February 14, 1979.

Title: An Evaluation of a Data-based Sex Education Training Program for Mentally Retarded Adults.

APPROVED BY MEMBERS OF THE THESIS COMMITTEE:
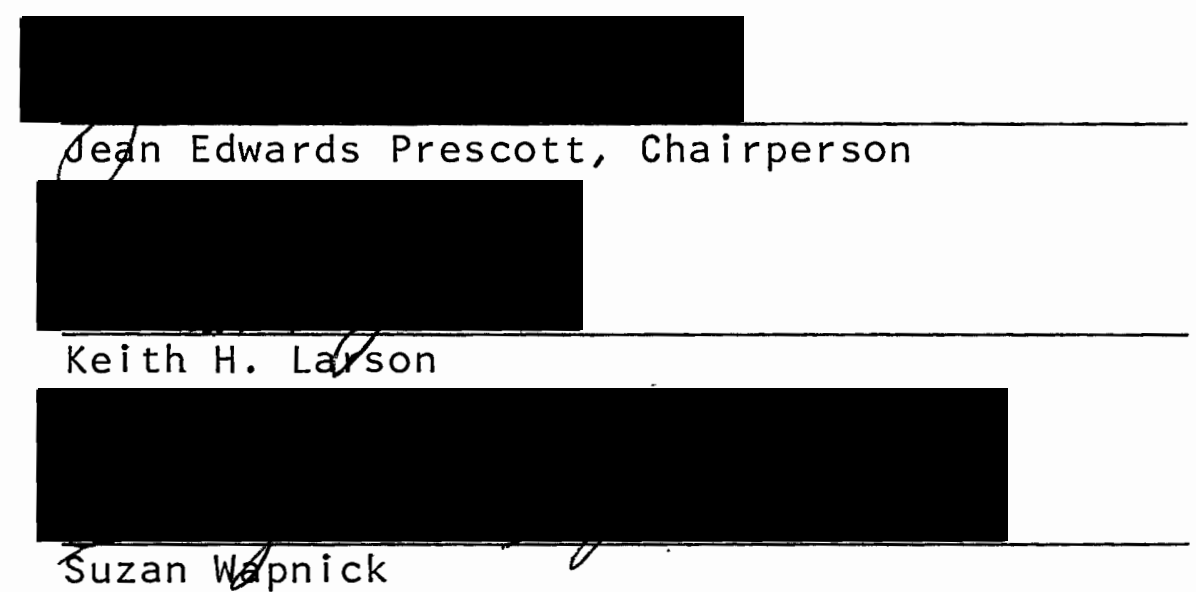

The study determined that twenty-three mildly to moderately retarded adults living within the community increased their sexual knowledge after attending a twelvemonth, data-based sex education training program. The Lane Community College-Adult Basic Education ( $L C C-A B E$ ) Pre/Post Test was administered to each subject when he/she began and finished the training program. The Intermittent Probe Tests were administered to each subject after instruction in each of thirteen topic areas in the curriculum. The main conclusions were that: (a) the subjects 
2

significantly increased their sexual knowledge after training; (b) class, sex, ability level, age, type of residence, and length of time in that residence were not significantly influential in the increase of sexual knowledge; and (c) a significant correlation between the Intermittent Probe Tests and post-test scores indicated a high degree of predictability between the two tests and that long-term (over a twelvemonth period) retention resulted from training. 
AN EVALUATION OF A DATA-BASED SEX EDUCATION TRAINING PROGRAM FOR MENTALLY RETARDED ADULTS

\author{
by
}

PATRICIA ANN RILEY

A thesis submitted in partial fulfillment of the requirements for the degree of

\author{
MASTER OF SCIENCE \\ in \\ EDUCATION
}

Portland State University 
TO THE OFFICE OF GRADUATE STUDIES AND RESEARCH:

The members of the Committee approve the thesis of Patricia Ann Riley presented February 14, 1979.
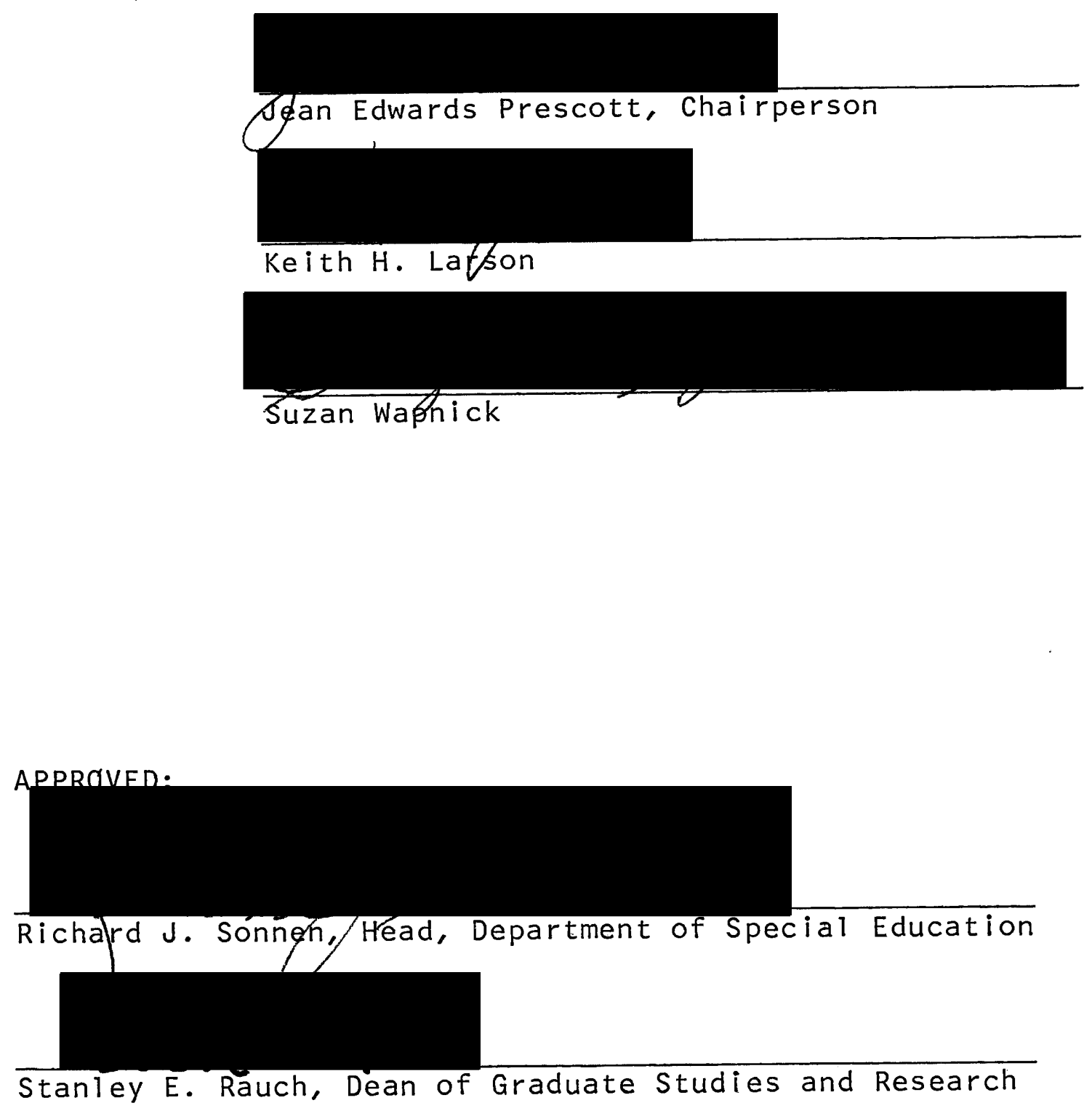
TABLE OF CONTENTS

PAGE

LIST OF TABLES . . . . . . . . . . . . . . . v v

LIST OF FIGURES . . . . . . . . . . . . . . v v

CHAPTER

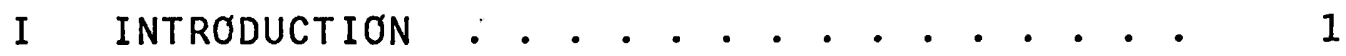

I I Review of the literature . . . . . . . . 3

The Historical Perspective . . . . 3

The Present Perspective...... . 4

I I CURRENT NEED FOR RESEARCH AND PROBLEM

STATEMENT . . . . . . . . . . . . . 7

IV DEFINITION OF TERMS . . . . . . . . . . . . . 9

LCC-ABE Sex Education Curriculum . . 99

Assessments . . . . . . . . . . 11

Activity Center......... . 12

Workshop . . . . . . . . . . 12

V METHODS ......................... 14

Subjects: Pilot Study ....... 14

Subjects: Field Study ....... 15

Measures ............ 16

LCC-ABE Pre/Post Test

Intermittent Probe Test 
Pilot Study

Field Study

VI

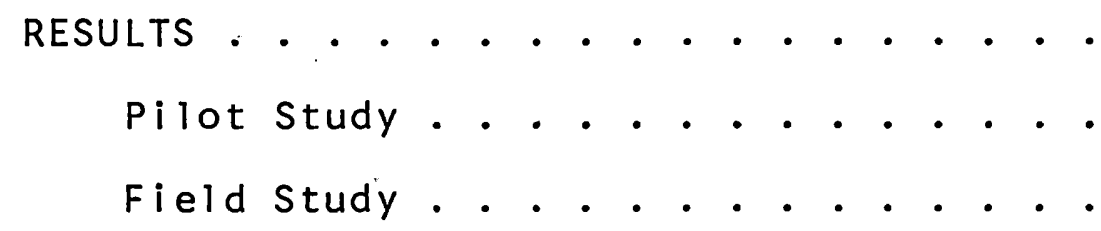

26

Pilot Study... . . . . . . . 26

Field Study . . . . . . . . . . 26

VII DISCUSSION . . . . . . . . . . 30

Pilot Study ........... . . 30

Field Study... . . . . . . . 30

Demographic Variables

Scattergram

Sexual Knowledge vs. Sexual

Behavior

Recommendations for Additional

Research.

REFERENCES

APPENDICES

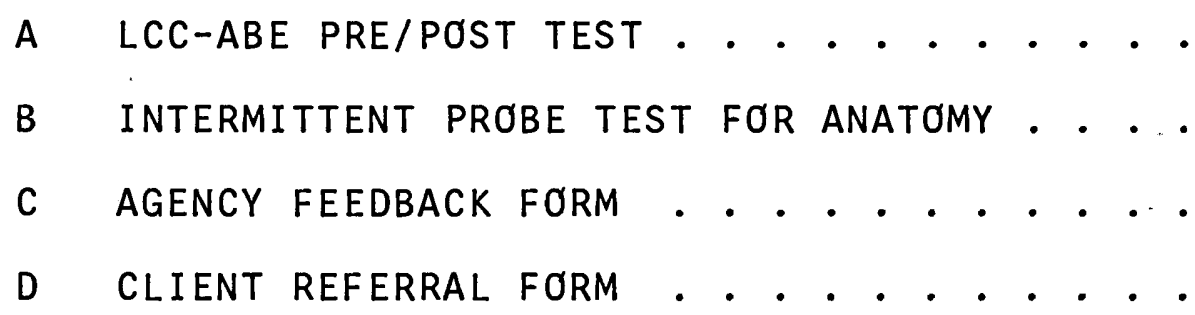

34

38

39

51

57

60 
TABLE

PAGE

I Results of the Analysis of Six Demographic

Variables in the Field Study . . . .

\section{LIST OF FIGURES}

F I GURE

PAGE

1. Scattergram Correlating the Intermittent

Probe Test Data with the Post-test

Data . . . . . . . . . . . . . . 


\section{CHAPTER I}

\section{INTRODUCTION}

Today, the main thrust of training programs for the mentally handicapped is the development of functional living skills. The ultimate goal of these training programs is for handicapped people to live as independent adults in society. Program developers have begun to realize that if mentally handicapped people are going to achieve full independence and acceptance by society, sex education must be built into existing programs.

Winifred Kempton (1976) defines sex education for the retarded by 1 isting the three major aspects of instruction:

1. Relationships: how we feel about ourselves in relation to family, friends, lovers, spouses, etc.; and behavior that results from these feelings.

2. Physiology of the human body: the respective male and female roles in reproduction; and the activity and feelings involved.

3. An understanding of the sexual impulses or erotic feelings we are born with: how they are aroused; and what is involved in their control.

Mastery of skills in each of these areas, and the development of responsible, adult behavior appears to be crucial to the successful independent functioning of retarded individuals. 
The Lane Community College-Adult Basic Education ( $L C C-A B E$ ) program acted on the need for sex education training for the retarded in June 1977 . Repeated incidences of public exposure and other inappropriate behaviors brought about the initiation of a three-month pilot study in Lane County. The purpose of the study was to examine the effects of sex education training on the behavior of mentalily retarded (MR) adults. Due to the success of the pilot study, a twelve-month field study was initiated in September 1977 to further examine the implications of data-based sex education instruction on the behavior of this population. The emphasis of both studies was functionalism rather than strict empiricism. That is, the empiricism of the research was sometimes compromised in order to maximize the functionality of instruction and application of information. The remainder of this paper is an evaluation of the study to determine if an increase in sexual knowledge occurred in students who participated in the sex education training program. 


\section{CHAPTER II}

\section{REVIEW OF THE LITERATURE}

To give added insight into this evaluation, a brief examination of past and present perspectives toward sex education for the mentally retarded will be presented.

\section{THE HISTORICAL PERSPECTIVE}

During the mid-sixties sex education for the mentally retarded was rarely considered an important component of curriculums and/or training programs (Gordon, 1971). Training in grooming and hygiene was the main component of so-called "social living skill programs." During the late sixties training and counseling in marriage and parenthood began to emerge (Abott \& Ladd, 1970; Bass, 1963., 1964; 19.14 Johnson, 1969). The emergence of training in these two areas marked the recognition of not only the sexuality of the retarded, but also their need for intimacy and closeness. However, the shortcoming of these early programs was their narrow scope. Alternatives to marriage were not considered, nor were topics dealing with self-defense against rape or venereal disease. The primary forms of birth control which were advocated were sterilization and separation of the sexes (Bass, 1974; Johnson, 1969). The 
treatment of these topics was a reflection of the attitude of our society toward sex education for the retarded during the $1960 \mathrm{~s}$.

\section{THE PRESENT PERSPECTIVE}

Today, the attitude taken toward sex education for the mentally retarded is much more humanistic. The spectrum of topics included in curriculums is much broader. Consideration of individual needs is of primary concern. Several articles advocating extensive sex education for the retarded have appeared in the literature (B10m, 1971; Friedman, 1971; Gorden, 1971a, 1971b; Johnson, 1973; Kempton, 1971; Maddock, 1974; Morgenstern; 19.73; Sengstock \& Vergason, 1973; Shindel1, 1975; Vockell \& Mattick, 1972). Seven primary reasons supporting sex education for the retarded appear throughout these articles:

1. The mentally retarded have the same psychosexual and physiological development that "normal" people do. Consequently, they have the same sexual needs and frustrations. They require information and training to deal with these needs effectively.

2. The mentally retarded receive the same sexual messages through the media and their environment that we all receive. However, due to their 1 imited social and intellectual skills, and possible isolation, they are not as 
well-equipped to process these messages and make sensitive, responsible decisions about their behavior.

3. Due to their lack of ability to process information, the mentally retarded are much more vulnerable sexually. They cannot afford to be sexually ignorant.

4. Parents and educators believe that giving the retarded information on sexual intercourse, masturbation, or even marriage will result in deviant behavior. However, the previously cited literature concludes that when given adequate information, the retarded's curiosity and need to experiment will. greatly decrease.

5. If the mentally retarded are to be mainstreamed into society, appropriate social and sexual behavior is mandatory. The retarded need training in social and sexual skills just as they need training in all other skill areas. In order to become fully independent adults, the retarded have a right to sex education.

6. Many parents and educators of the mentally retarded believe sex education should and does, in fact, come from the home. However, the literature indicates that this is not the case (Edmonson \& Wish, 1975; Floor, Rosen, Baxter, Horowitz, \& Weber, 1971; Hal1 \& Morris, 1976; Hal1, Morris, \& Barker, 1973; Hammer, Wright, \& Jensen, 1967; Gordon, 1975)? The high incidence of illegitimate pregnancies, teenage marriages, veneral disease, and illegal 
sexual activity indicates a deficiency in sex education training.

7. Repression of sexual desires has been advocated as a substitute for sex education for the retarded. However, education is the most logical and humanistic alternative to repression (Floor et al., 1971). 


\section{CHAPTER III}

\section{CURRENT NEED FOR RESEARCH AND PROBLEM STATEMENT}

A review of the 1 iterature on sex education for the retarded indicates that to the author's knowledge only six data-based articles (Edmonson \& Wish, 1975; Floor et al... 1971; Hall \& Morris, 1976; Hall et al., 1973; Hammer et al.. 1967; Hamre-Nietupski \& Williams, 1977) currently exist. Five of these studies are based on assessments of sexual attitudes and knowledge in mentally retarded adolescents and adults not involved in sex education programs. The Hamre-Nietupski \& Williams study is the only identified evaluation of a sex education training program. Currently, a need exists for further examination of sex education training programs. Hopefully, the following study will begin to fulfill at least a portion of the need for program evaluation and research.

The purpose of this evaluation was to determine whether or not an increase in knowledge of sex education appeared in students who attended the LCC-ABE sex education program. The null hypothesis for the evaluation is the following: there is no difference in sexual knowledge as measured by the LCC-ABE Pre/Post Test and the 
Intermittent Probe Test for adult MRs attending the LCC-ABE sex education course. The Pre/Post Test was administered to each student as he/she entered and left the training program. The Intermittent Probe Test was administered to each student following instruction in a given topic area throughout the twelve-month field study. 
CHAPTER IV

\section{DEFINITION OF TERMS}

The following terms will be defined at this time:

Sex education

LCC-ABE Pre/Post Test

Intermittent Probe Test

Activity center

Workshop

For the purpose of this evaluation, sex education will be defined by briefly describing each of the topic areas covered in the curriculum. A copy of the curriculum is available from the Sex Education Training Program Administrative Committee for examination.

\section{LCC-ABE SEX EDUCATION CURRICULUM}

1. Relationships: how people interact with each other, the types of relationships we have in our lives, different ways of showing affection, the difference between liking and loving, and the responsibilities of friendship are the main areas covered in this topic.

2. Grooming: maintaining and choosing appropriate clothing are covered in this topic. Also discussed are the reasons for good grooming. 
3. Hygiene: this topic covers bodily cleanliness, menstruation, and puberty. Also discussed are the reasons for good hygiene.

4. Anatomy: labeling and identifying the functions of the genitals, breasts, nipples, anus, urethra, and navel are included in anatomy.

5. Masturbation: the mechanics of masturbation, appropriate and inappropriate places to masturbate, and reasons for masturbating are covered in this area.

6. Sexual Intercourse: the mechanics of intercourse, appropriate and inappropriate places and partners, and responsibilities involved in sexual intercourse are discussed.

7. Pregnancy: the signs of pregnancy, how it occurs, discussion of the birthing process, who to ask for help if pregnancy is suspected, and how to prevent pregnancy are covered in this topic.

8. Birth Control: the purpose of birth control, who uses it, how it is used, where to obtain it, and the labeling of each device are covered under birth control.

9. Venereal Disease (VD): the symptoms of VD, who to ask for help, how it is contracted, and how it can be prevented are discussed.

10. Marriage: the necessary skills for marriage, responsibilities involved in marriage, establishing a 
realistic view of marriage and its alternatives are covered in this topic area.

11. Children: the necessary skills for raising a family, the responsibilities and commitments involved, and the pitfalls and pleasures of child rearing are discussied.

12. Homosexuality: homosexuality is discussed as an alternative in intimate relationships. The responsibilities and social repercussions for this type of life style are discussed.

13. Inappropriate and Illegal Sexual Activity: appropriate and inappropriate places and/or partners for sexual activities are discussed. Also covered are the repercussions for irresponsible sexual behavior. Rape and how to prevent and/or defend against it are covered. Possible illicit approaches from a homosexual are also discussed.

\section{ASSESSMENTS}

The Lane Community College-Adult Basic Education Pre/Post Test is an itemized, nonstandardized test covering the essential elements of each topic area. (Refer to Appendix A for a copy of the test.) The test was developed by the program administrators specifically for this program. A complete discussion of this instrument appears in Chapter V. 
The Intermittent Probe Test was also developed for this training program. The probes were administered after instruction of each topic area. Refer to Appendix B for an example of an Intermittent Probe Test on anatomy. A complete discussion of the probes appears in Chapter $V$.

\section{ACT IVITY CENTER}

The primary function of an activity center is instruction in the areas of grooming, hygiene, social skills, recreation, functional academics, and pre-vocational skills. Clients in activity centers are not eligible for high school programs and are generally not skilled enough for employment in sheltered workshops. They usually reside with their families, in foster homes, group homes, or nursing homes. An activity-center-level course was taught in both the pilot study and the field study. The students in these courses attended an activity center forty hours per week.

WORKSHOP

The primary function of a workshop is employment, rather than training. Employees are generally paid on a piece rate through contracts solicited from businesses within the community. The ultimate goal for most clients in sheltered workshops is competitive employment. These clients usually live with their families, in group homes, 
foster homes, or independently. Workshop-level courses were taught in both the pilot study and the field study. The students in these courses worked in a workshop forty hours per week. 
CHAPTER $V$

\section{METHODS}

\section{SUBJECTS: PILOT STUDY}

Subjects who participated in the pilot study were referred by their work supervisors, group home coordinators, or parents. The referrals were based on needs exhibited by the clients. For example, some students were referred because of inappropriate sexual behavior. Others were referred because of a need to develop appropriate marriage, social, grooming, or hygiene skills. Still other referrals were made because of a newfound interest in the opposite sex, coupled with an inadequate means of expressing that interest. Due to the remedial nature of the training program, subjects were not chosen randomly, nor was a control group used.

Two courses were taught during the pilot study: an activity-center-level course and a workshop-level course. The activity-center-level course was composed of two men and four women from two local activity centers. The students were considered low functioning, trainable mentally retarded (TMR). They lived either with their parents, in group homes, or nursing homes. Their ages ranged from twenty to thirty years. All students attended an activity center on a full-time basis. 
The workshop-level course was composed of three men and three women from two local sheltered workshops. The students were considered high functioning TMR to high functioning, educable mentally retarded (EMR). They 1 ived either with their parents, in group homes, or alone in: apartments. Their ages ranged from twenty to forty years. All students worked full-time in a sheltered workshop. Included in the workshop course were three couples, two of whom were engaged to be married.

Three students dropped out of the study by the end of September 1978. One student dropped out due to previous mastery of the material and two dropped out due to embarrassment of the subject matter.

\section{SUBJECTS: FIELD STUDY}

The subjects who participated in the twelve-month field study were referred by the same resources the pilot study subjects were referred. These subjects were also referred for the same reasons as the pilot study subjects. Again, due to the remedial nature of the training program, subjects were not chosen randomily and a control group was not used.

Three courses were taught during the field study:

(1) an activity-center-level course, (2) a beginning workshop-level course, and (3) an advanced workshop-level course. A total of forty-one students received some 
training over the twelve-month period: thirteen at the advanced workshop level, sixteen at the beginning workshop level, and twelve at the activity center level. By September 1978, eighteen subjects had dropped out of the program, leaving twenty-three as the total sample. These twentythree subjects received training for twelve months over the entire curriculum.

The eighteen subjects who dropped out of the study left for various reasons. These reasons included embarrassment, moving out of the area, changing jobs, and parental request. One student left due to her inability to learn in a group setting.

The subjects in the final sample ranged in age from twenty to sixty-one years. All subjects worked full-time in a sheltered environment, either an activity center or a sheltered workshop. Each student lived in one of the following types of residences: (a) with his or her parents, (b) with a foster parent, (c) in a group home, (d) in a nursing home, or (3) independently in an apartment. The students' ability levels ranged from low TMR to high EMR.

\section{MEASURES}

Two testing instruments were used during the course evaluation. The first instrument was the LCC-ABE Pre/Post Test, and the second was the Intermittent Probe Test. 


\section{LCC-ABE Pre/Post Test}

The LCC-ABE Pre/Post Test was developed by the administrative staff of the sex education program. Several of the test items were drawn from the "Sexual Knowledge Questionnaire for the Mentally Handicapped Adult" which was " developed at the Portland Rehabilitation Center. A malefemale sex education instructional team wrote the questionnaire. The purpose of the test was to establish the following information: (a) level of sexual knowledge prior to instruction, (b) the amount of long-term retention over twelve months, (c) experiential background, and (d) possible long-term goals of marriage and/or child rearing. Test validity has not been established on this assessment.

Test Items. The first five items on the test determined the students' past experiences with sex education, their interest in the course, and their willingness to talk about sex. The remaining items dealt with (a) past experiences with masturbation, sexual intercourse, and dating;

(b) future goals for marriage and child-rearing; and (c) level of general sexual knowledge.

Test Mechanics. Due to the functionalism of the training programming, test administration was not handled in a highly empirical manner. The pre/post test was given on a one-to-one basis, usually male-to-male or female-tofemale, by an instructor or aide. The test required twenty-five to thirty-five minutes to complete. It was 
administered at either the student's place of employment (workshop or activity center) or during class. The pre/ post test was administered when each student began and finished the program. During the post-testing, a list of questions with samples from each topic area was also administered to each student. This list of questions, along with the post-test, was used as a comparative measure with the Intermittent Probe Tests to determine long-term retention and predictability of the pre/post test and the probes.

\section{Intermittent Probe Test}

The purpose of the Intermittent Probes was to determine the amount of retention after instruction in each topic area. For example, if the subjects required one month of instruction to reach mastery on a topic area, the probes were then given the following instructional session, from one to three days later. The probe system was introduced to the program during winter quarter, 1978. When first initiated the post-instructional probes were coupled with pre-instructional probes. The purpose of the pre/post probe system was to determine more specifically what each subject had learned during instruction of a given topic area. Also, the probe system would have added to the internal validity of the study. However, due to the lack of time and personnel, the pre-instructional probe was eliminated. Test validity was not established on the Intermittent Probe Test. 
Test Items. The test items were drawn from the specific behavioral objectives of each topic area. The length of each set of probes varied considerably--from forty-two questions in the birth control section to five questions in the venereal disease section. Responses to test items were either verbal or non-verbal. The verbal responses required either a label or a description, while the non-verbal responses required pointing to an object or picture.

Test Mechanics. Once again, due to the practicality of the testing situation, administration was not highly empirical. The Intermittent Probe Test was given on a one-to-one basis, usually male-to-male or female-to-female, by the instructor or aide. The students were drawn out of the ongoing class session to an adjoining room and given the Intermittent Probe Test. Administration of the probes required approximately five to ten minutes per person.

\section{PROCEDURE}

\section{Pilot Study}

During the fall of 1976 the author and several representatives of agencies serving the mentally retarded in Lane County met to discuss the need for a sex education program for their clients. This meeting was stimulated by several incidents of exposure and other inappropriate sexual behaviors involving the retarded population in Lane County. 
Administrative and curriculum committees were organized during the first meeting. The purpose of the administrative committee was to locate a funding source, establish a classroom, develop job descriptions for the teaching staff, and determine the basic structure of the program: The purpose of the curriculum committee was to research existing sex education curriculums and 1 iterature, and develop a curriculum for the Lane County program.

Lane Community College, Adult Basic Education Program was established as the funding source. During the pilot study, the Lane Community College Downtown Activity Center was used as the classroom.

Two courses were taught during the pilot study, an activity-center-level course and a workshop-level course, twelve student in all. The workshop-level course met once a week for two hours and the activity-center-level course met twice a week for one a a half hours each.

Job descriptions for the teaching staff included one male and one female instructor, both with experience in the following areas: (a) working with the mentally retarded, (b) sex education, (c) data-based programming, and (d) behavior management techniques.

Before the courses began the two instructors visited the two activity centers and two sheltered workshops to become acquainted with the students. Due to the sensitivity of the subject matter, the instructors felt it was 
important to begin to establish trust and acceptance as soon as possible.

In addition to student-teacher trust, it was assumed that teacher-teacher trust and acceptance was also very important. Prior to the beginning of instruction the teachers spent several hours in discussion and training sessions to establish mutual comfort. The establishment of consistency in philosophy and attitude toward the subject matter was also established in the training sessions. Being honest, open, and objective about the information given to the students was of primary concern to the instructors. Clarity of the instructors' attitudes toward sex and comfort with their own sexuality was also assumed to be important .

After instruction had begun, a parent meeting was held to familiarize the parents with the sex education program. The instructional and administrative staffs encountered fear and hostility among the parents. In retrospect it seems likely that these negative feelings could have been minimized had the parent meeting been held prior to the beginning of instruction. The parents expressed a need for better understanding of the subjects being taught and the values expressed by the staff to the students.

Pre-testing using the LCC-ABE Pre/Post Test was done during the first few class sessions. However, it soon became clear that pre-testing during class was too much of a 
drain of instructional time. The remainder of the pretesting was completed at each student's work site.

The instructional method used was direct instruction with immediate informational feedback. Direct instruction is when the instructor verbalizes a piece of informaticin and asks a student to repeat it. For example, while pointing to a drawing of a male figure the instructor would say to an individual student, "This is a man. John, what is this?" If the student's response was correct the instructor verbally praised the student. If the student's response was incorrect the instructor says, "No" and gives the correct answer, again repeating the original question, "What is this?" While using direct instruction, the teachers utilized examples, synonyms; or definitions in the development of concepts. This method of instruction was used with all ability levels. Appropriate audiovisual support materials were also used. The students and teachers sat in a close circle of chairs to increase communication. The daily instructional format included the following:

1. Class began with a brief question-and-answer review of the material discussed in the previous class session.

2. Next, the day's topic was introduced with a brief outline of what was to be covered during the session. 
3. Direct instruction of the topic was used with immediate informational feedback. Instruction was supplemented with audiovisual materials.

4. Class ended with a brief review of what had been discussed during the class session.

The two instructors alternated coverage of each step in the instructional format. One instructor was primarily responsible for coverage of each step; however, the alternate instructor could supplement information if necessary. If the Intermittent Probe Test was to be given during a class session, one instructor ran the entire class while the other instructor administered the probes.

During the pilot study, instruction went at a very rapid pace. Though the data were significant, the pace appeared to be too rapid for the students. The purpose of this pace was to allow the entire curriculum to be taught to determine its functionality.

\section{Field Study}

The same instructional method and the same format used in the pilot study were used in the field study. During the twelve months two replacements were made in the teaching staff and approximately five changes occurred in the volunteer administrative staff. New client referrals were selected for the field study. The curriculum remained basically the same with minor expansions in several topic areas. Due to its proximity to public transportation, a 
private room in the public library was chosen as the new meeting site for the field study.

Two major modifications occurred during the field study. First, the program was expanded to three classes: (a) an activity-center-level course, (b) a beginning workshop-level course, and (c) an advanced workshop-level course. The beginning and advanced workshop-level courses met once a week for two hours each. The activity-centerlevel course met twice a week for one and a half hours. The expansion of the workshop-level course to beginning and advanced levels was done to improve instruction through homogeneity of the students' abilities.

Secondly, the pace at which the course was taught was considerably slower. Instruction moved at a pace dictated by the students' grasp of the information.

The activity-center-level and beginning workshoplevel courses completed the curriculum in approximately twelve months, averaging three topic areas per quarter. The advanced workshop-level course completed the curriculum in approximately nine months, averaging four topic areas per quarter.

During the field study, two information forms were added to the program procedure. During fall quarter the Agency Feedback Form (see Appendix C) was introduced. The purpose of this form was to give the referring agencies information on client progress and to better coordinate 
25

agency/classroom training efforts. During spring quarter the Client Referral Form (see Appendix D) was developed. The referral form was developed to provide more client information to the instructors during the referral process. Both forms were initiated to improve communication and training efforts between the referring agencies and the program instructors. 
CHAPTER VI

RESULTS

PILOT STUDY

A significant difference between pre- and post-test scores on the LCC-ABE Pre/Post Test was found for the activity-center-level and workshop-level courses $(t=4.71$; $d f=8 ; p<.002)$. Data for the two courses were combined for statistical analysis due to the small n. A total of nine subjects was used in the pilot study due to three subjects dropping out. The $t$ test for differences between non-independent means (Bateman, 1977; Drew, 1976) was the statistic used in the pilot study. The data were interval in nature and appeared to be normally distributed. The $n$ size was too small to meet the requirements of a parametric statistic; however, due to the "robustness" of the statistic its use with an $n$ smaller than twelve was acceptable (Batemen, 1977).

\section{FIELD STUDY}

A significant difference between pre- and post-test scores on the LCC-ABE Pre/Post Test was found in the activity-center-level course $(t=9.82 ; d f=5 ; p<.002)$, the beginning workshop-level course $(t=7.39 ; d f=6$, 
$p<.002)$, and the advanced workshop-level course $(t=10.3$; $d f=9, p<.002)$. An $n$ of six was used in the activity center level, an $n$ of seven in the beginning workshop level, and an $n$ of ten in the advanced workshop level. The total sample was twenty-three. The $t$ test for differences between non-independent means (Bateman, 1977; Drew, 1976) was also the statistic used in the field study. Once again, the data fulfilled all the previously described requirements for the use of this statistic except sample size. However, due to the robust nature of the test its use with a small n was acceptable.

In addition to the pre/post test data, intergroup comparisons of gain scores on the post-test were completed on six independent variables: (a) class, (b) sex, (c) ability level, (d) age, (e) type of residence, and (f) length of time in that residence. An $n$ of twenty-three was used with each variable. A one-way analysis of variance for repeated measures (one-way ANOVA) was applied to each variable and each was not significant (see Table I). The data appeared to fulfill all of the requirements necessary for the use of the one-way ANOVA (Drew, 1976). These requirements include the following: (a) interval data, (b) adequate sample size, (c) assumed normal distribution of data, and (d) one experimental variable with three or more data points. 
TABLE I

RESULTS OF THE ANALYSIS OF SIX DEMOGRAPHIC VARIABLES IN THE FIELD STUDY

\begin{tabular}{|c|c|c|c|c|}
\hline & Variable & $\mathrm{F}$ & $d f$ & $p$ \\
\hline (a) & Class & 1.039 & $2 / 20$ & $>.05$ \\
\hline (b) & Sex & .071 & $1 / 21$ & $>.05$ \\
\hline (c) & Ability level & 2.412 & $1 / 21$ & $>.05$ \\
\hline (d) & Age & .785 & $10 / 12$ & $>.05$ \\
\hline (e) & Type of residence & .0361 & $1 / 21$ & $>.05$ \\
\hline$(f)$ & $\begin{array}{l}\text { Length of time in } \\
\text { residence }\end{array}$ & .100 & $1 / 21$ & $>.05$ \\
\hline
\end{tabular}

A third statistical analysis was completed in the field study. The Intermittent Probe Test data were correlated through the use of a scattergram with the post-test data and the data from the supplemental questions administered during the post-testing (Matheson, 1970). Figure 1 indicates that a strong correlation exists between the two. An $n$ of thirteen was used on the scattergram due to incomplete data on the remaining ten subjects. 


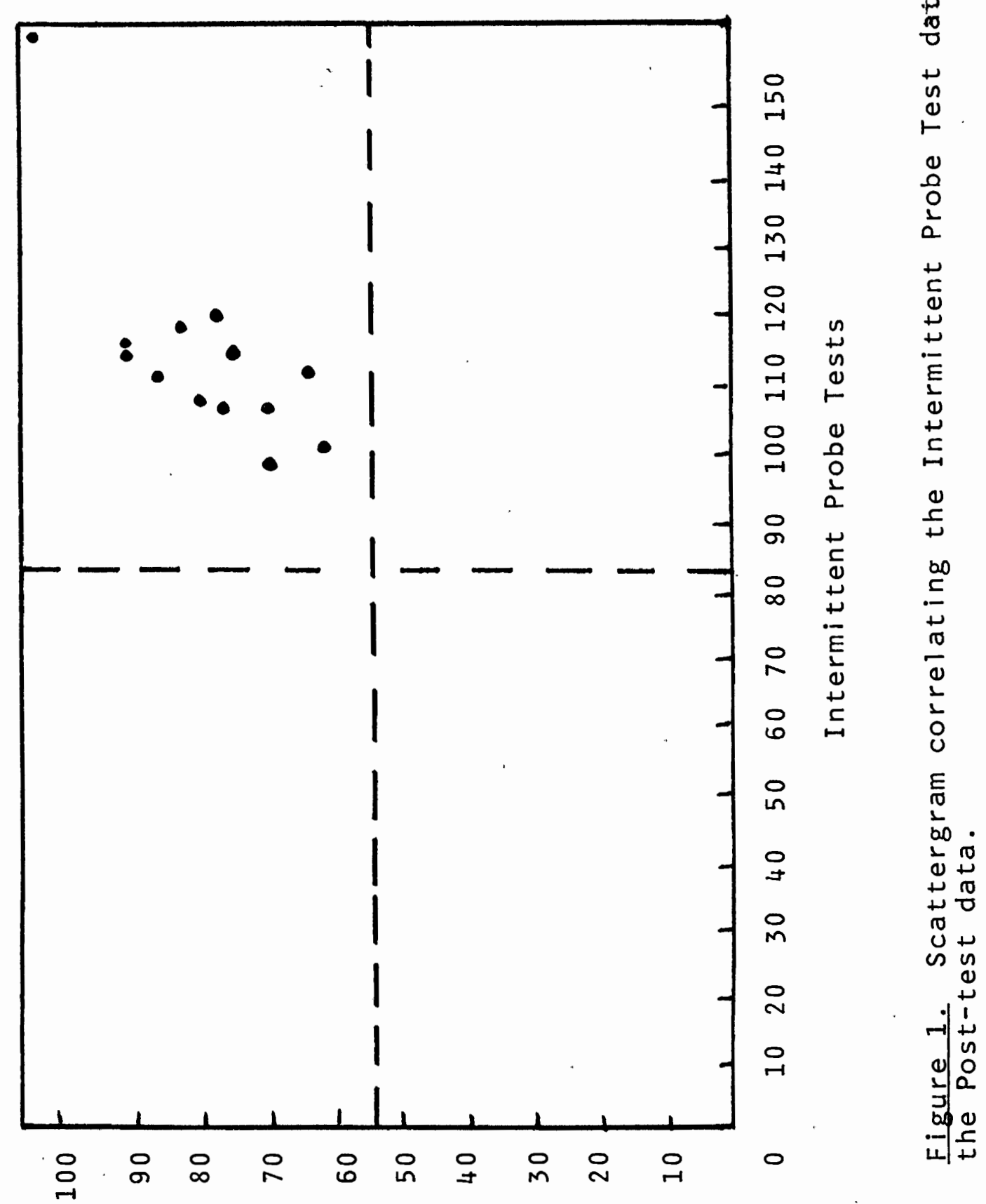

Post-test with Supplemental Questions 


\section{CHAPTER VII}

\section{DISCUSSION}

\section{PILOT STUDY}

Students who participated in the three-month pilot study significantly increased their sexual knowledge as measured by the LCC-ABE Pre/Post test. The results of the study were brief and somewhat inconclusive but significant enough to warrant the subsequent twelve-month field study.

\section{FIELD STUDY}

The post-test scores of the twenty-three subjects in the field study all improved significantly over pre-test scores. The nonsignificance of the six demographic variables added considerable strength to the pre/post test results. The increase in sexual knowledge appeared to be a direct result of the sex education training program and was apparently not influenced by class, sex, ability level, age, type of residence, or length of time in that residence.

Demographic Variables

No significant difference in gain scores between the three classes was found. Therefore, time of day, day of 
the week, the instructor, or differences in presentation of the material apparently did not affect learning. In addition, no significant difference in the gain scores of the EMR and TMR subjects was found. The possible indication of this result is that both low functioning and high functioning students were able to increase their sexual knowledge through a direct instruction training program. Also, no significant differences were found in the gain scores of males and females or between age groups, ranging from twenty to sixty-one years. The possible implication is that past experiences or past training did not significantly influence learning. Finally, no significant difference in gain scores was found in subjects from the five types of living environments. These environments were: (a) group homes, (b) nursing homes, (c) foster homes, (d) parents' homes, and (e) independent living. These results may indicate that incidental learning or practice of learned skills occurred equally in all types of residences. Therefore, clients from all living environments may improve their sexual knowledge through training.

\section{Scattergram}

The strong correlation depicted on the scattergram between the post-test with supplemental questions and the Intermittent Probes may indicate that predictability exists between the two assessments. That is, if a subject scored high on the probes he or she would also score high on the 
post-test. Another possible indication is that subjects were able to retain the information learned during instruction over several months. Subjects who scored high on the anatomy probe given in January also scored high on the anatomy portion of the post-test, given the following september.

\section{Sexual Knowledge vs. Sexual}

\section{Behavior}

All of the data examined indicate a significant improvement in the amount of sexual knowledge of the subjects. Throughout the discussion of data no mention has been made regarding the improvement of sexual behavior of the students. Standardized, objective assessments to measure the sexual knowledge of mentally retarded people are in existence. However, to the author's knowledge, no such assessments exist to measure this population's sexual behavior; that is, the students' functional implementation of sexual knowledge. Students are increasing their sexual knowledge through training programs but may not be exhibiting appropriate sexual behaviors outside the classroom. Improved assessment techniques are needed to increase the functionality of sex education training programs.

\section{Recommendations for Additional}

\section{Research}

The results of this study were strongly significant. However, it is possible that they only apply to a similar population. In order to give added strength to these 
results additional research using an improved design would be necessary. A time series design would help to eliminate the many threats to internal and external validity created by a pre/post test design. Also, a larger sample would add to the strength of the results. 


\section{REFERENCES}




\section{REFERENCES}

Abbott, J. M. \& Ladd, G. M. ". . . any reason why this mentally retarded couple should not be joined together.." Mental Retardation, 1970, 8, 45-48.

Bass, M. S. Marriage for the mentally deficient. Mental Retardation, 1974, 2, 198-202.

Bass, M. S. Marriage, parenthood, and prevention of pregnancy. American Journal of Mental Deficiency, 1963, 68, $318-324$.

Bateman, B. Statistics for the irreverent. Unpublished article, University of Oregon, 1977.

Blom, G. E. Some considerations about the neglect of sex education in special education. The Journal of Special Education, 1971, $5,359-361$.

Drew, C. Introduction to designing research and evaluation. Saint Louis: C. V. Mosby Company, 1976.

Edmonson, B. \& Wish, J. Sex knowledge and attitudes of moderately retarded males. American Journal of Mental Deficiency, 1975, 우, 172-179.

Floor, L., Rosen, M., Baxter, D., Horowitz, J., \& Weber, C. Socio-sexual problems in mentally handicapped females. The Training School Bulletin, 1971, 68, 106-112.

Friedman, E. Missing in the life of the retarded individual, sex: Reflections on Sol Gordon's paper. The Journal of Special Education, 1971, $\underline{5}, 365-368$.

Gordon, S. ". . . But where is sex education?" The Education Digest, $1978,43,50-52$.

Gordon, S. Missing in special education: Sex. The Journal of Special Education, 1971, $\underline{5}, 351-354$.

Gordon, S. Okay, let's tell it like it is (instead of just making it look good). The Journal of Special Education, $1971,5,379-381$. 
Hall, J. E. \& Morris, H. L. Sexual knowledge and attitudes of institutionalized and noninstitutionalized retarded adolescents. American Journal of Mental Deficiency, 1976, 80, 382-387.

Hal1, J.E., Morris, H. L., Barker, H. R. Sexual knowledge and attitudes of mentally retarded adolescents. American Journal of Mental Deficiency, 1973, 77, 706-709.

Hammer, S. L., Wright, L. S., \& Jensen, D. L. Sex education for the retarded adolescent: A survey of parental attitudes and methods of management in fifty adolescent retardates. Clinical Pediatrics, 1967, $\underline{6}$, 621-627. (Abstract)

Hamre-Nietupski, S. \& Williams, W. Implementation of selected sex education and social skills to severely handicapped students. Education and Training of the Mentally Retarded, 1977, 12, 364-372.

Johnson, W. R. Sex education and the mentally retarded. The Journal of Sex Research, 1969, $\underline{5}, 179-185$.

Johnson, W. R. Sex education of the mentally retarded. In F. de la Cruz \& G. D. LaVeck (Eds.), Human Sexuality and the Mentally Retarded. New York: Brunner/Mazel Publishers, 1973.

Kempton, w. Guidelines for training in sexuality and the mental ly handicapped. Planned Parenthood Association of Southern Pennsylvania, 1976.

Maddock, J. Sex education for the exceptional persons: A rationale. Exceptional Child, 1974, 40, 273-278.

Matheson, D., Bruce, R., \& Beauchamp, K. Introduction to experimental psychology. New York: Holt, Rinehart and Winston, Inc., 1970.

McNab, W. The sexual needs of the handicapped. The Journal of School Health 1978, 48, 301-306.

Morgenstern, M. The psychosexual development of the retarded. In F. de la Cruz \& G. D. LaVeck (Eds.), Human Sexuality and the Mentally Retarded. New York: Brunner/Mazel Publishers, 1973.

Publication Manual of the American Psychological Association. Baltimore, Md.: Garamond/Pridemark Press, Inc., 1974. 
37

Rosen, M. Conditioning appropriate heteroxesual behavior in mentally and socially handicapped populations. The Training School Bulletin, 1970, 66, 172-177.

Sengstock, W. L. \& Vergason, G. A. Issues in sex education for the retarded. Education and Training of the Mentally Retarded, $1973,5,99-103$.

Shindel1, D. E. Sex education programs and the mentally retarded. The Journal of School Health, 1975, 35. $88-90$.

Vockell, E. \& Natick, P. Sex education for the mentally retarded: An analysis of problems, programs, and research. Education and Training of the Mentally Retarded, 1972, 7, 129-134. 
APPENDICES 


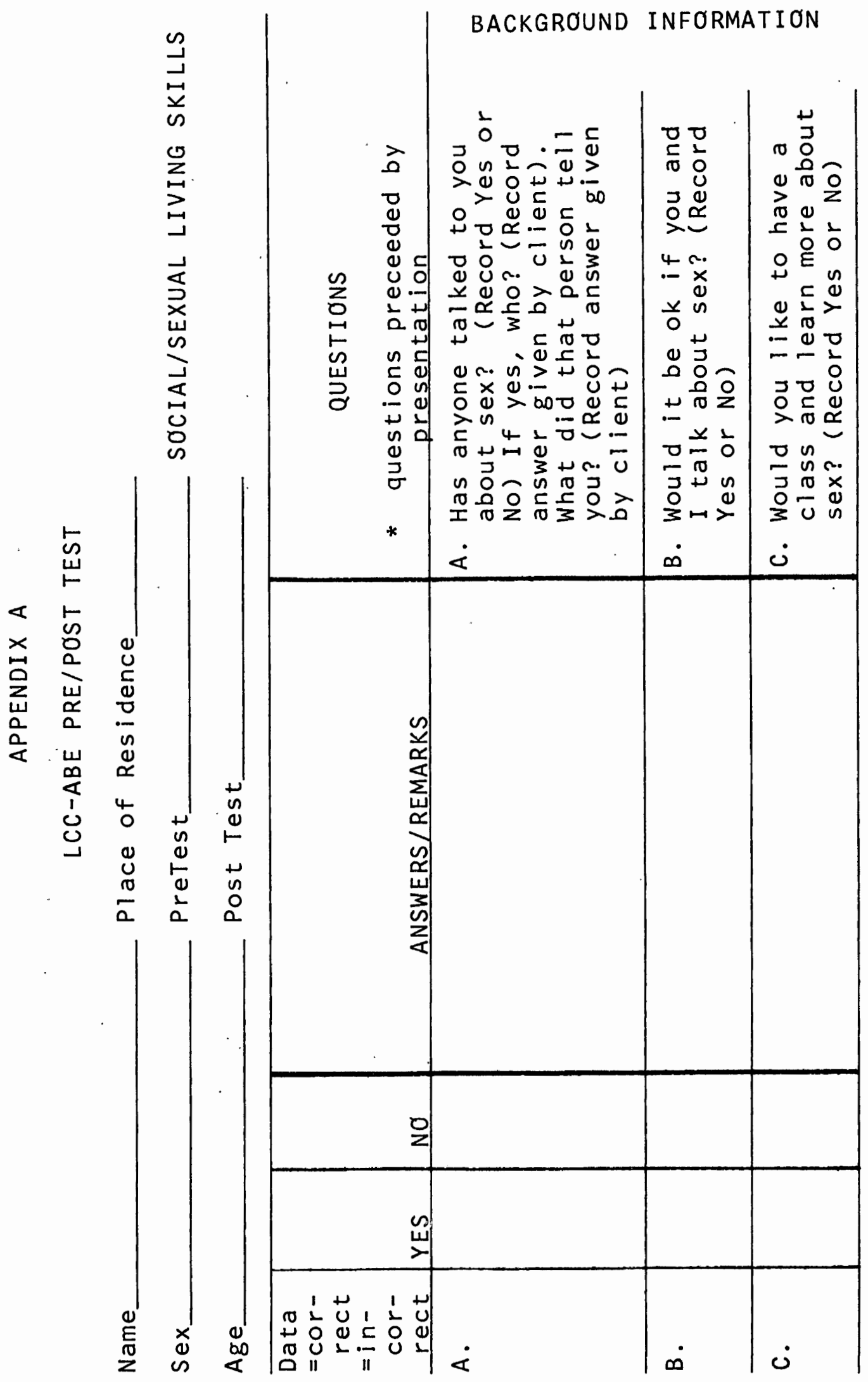




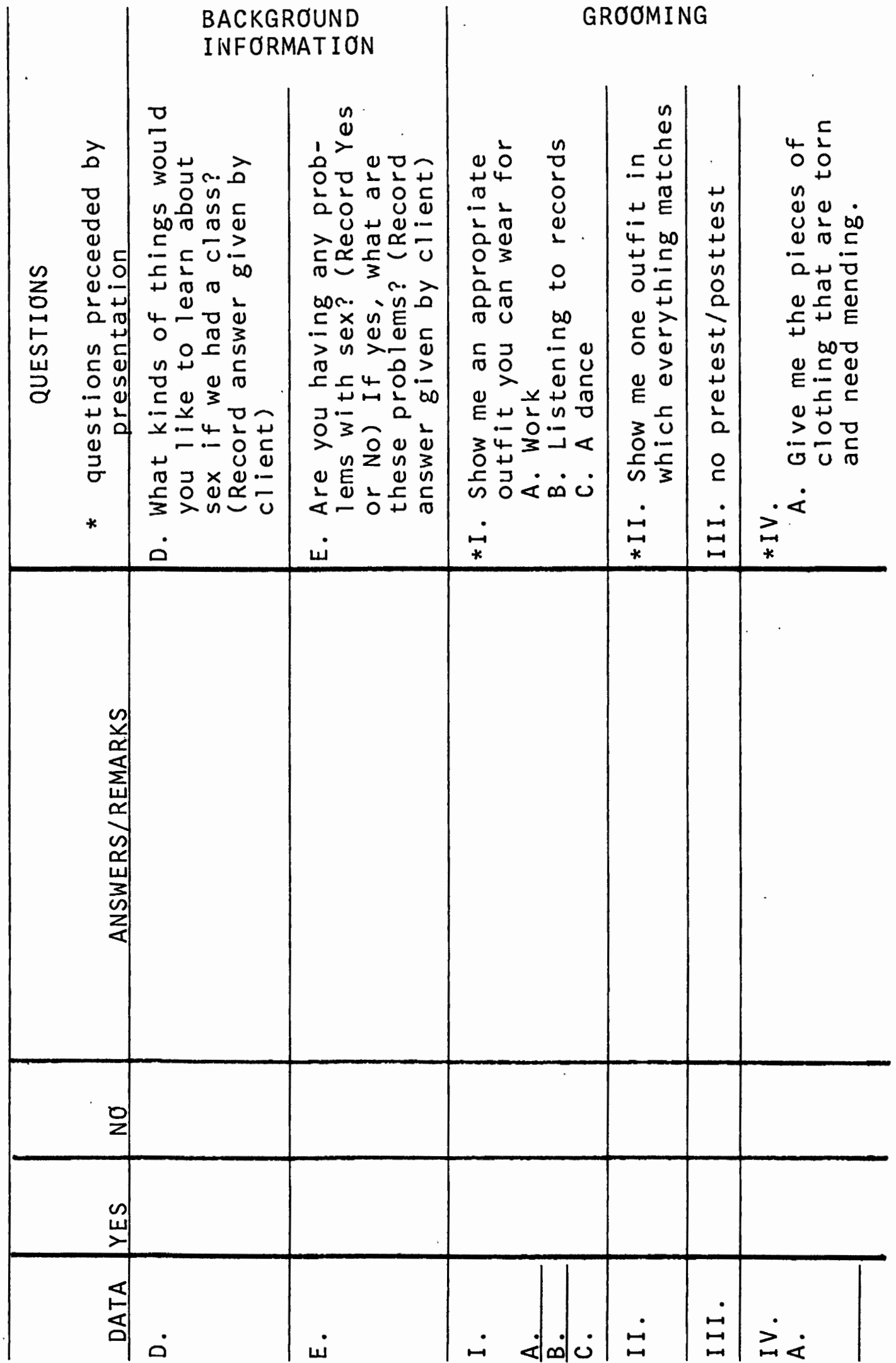




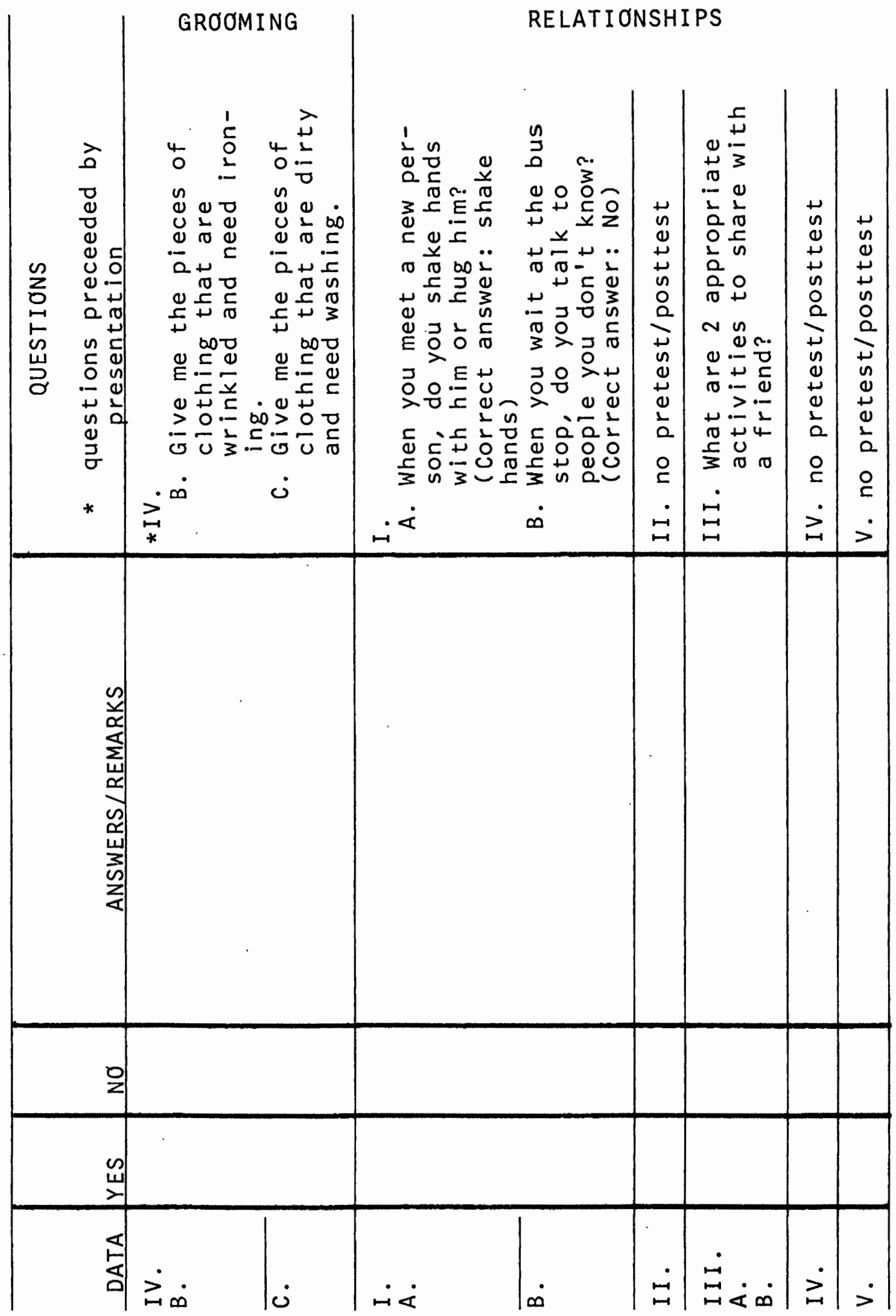




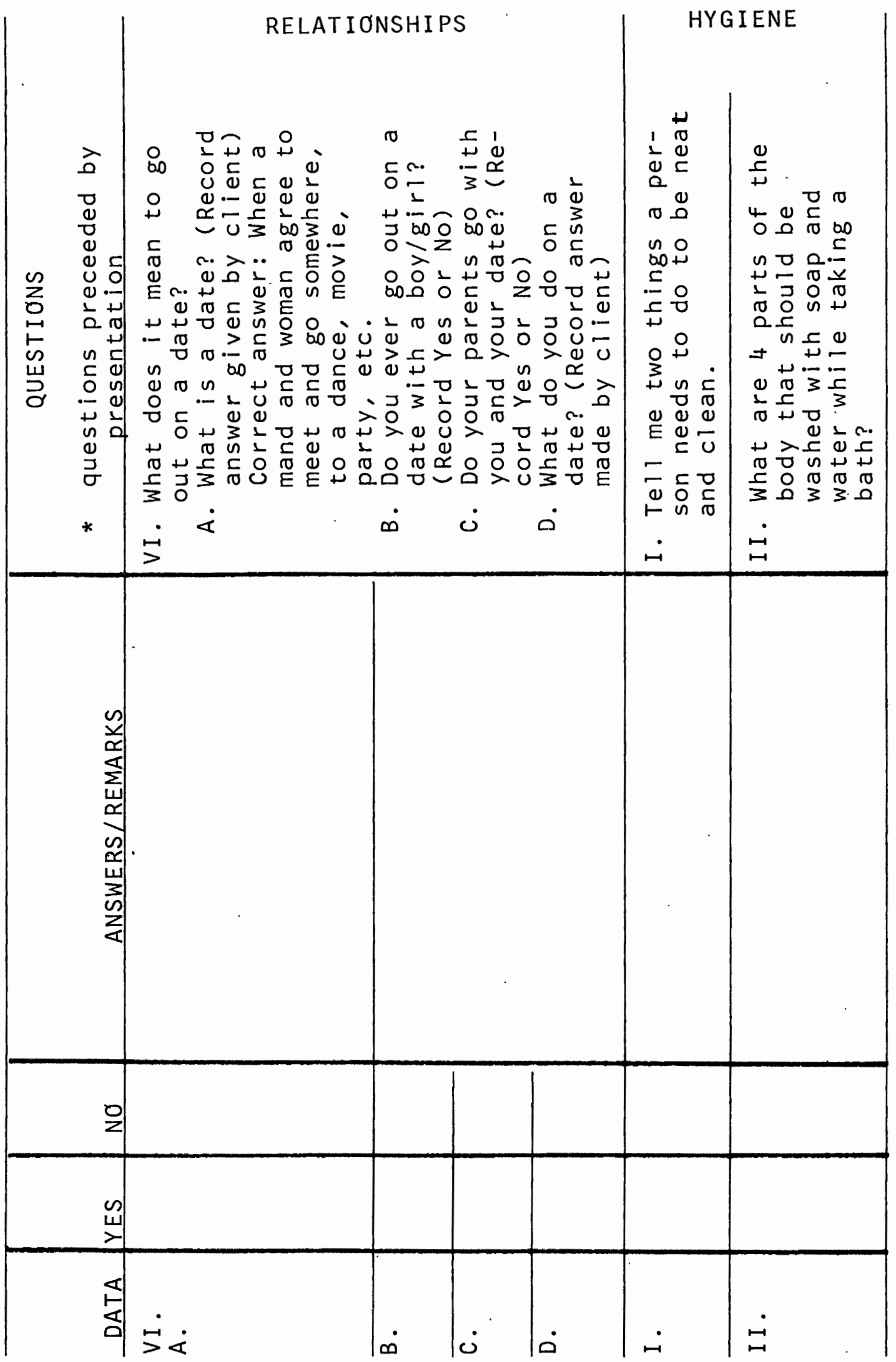




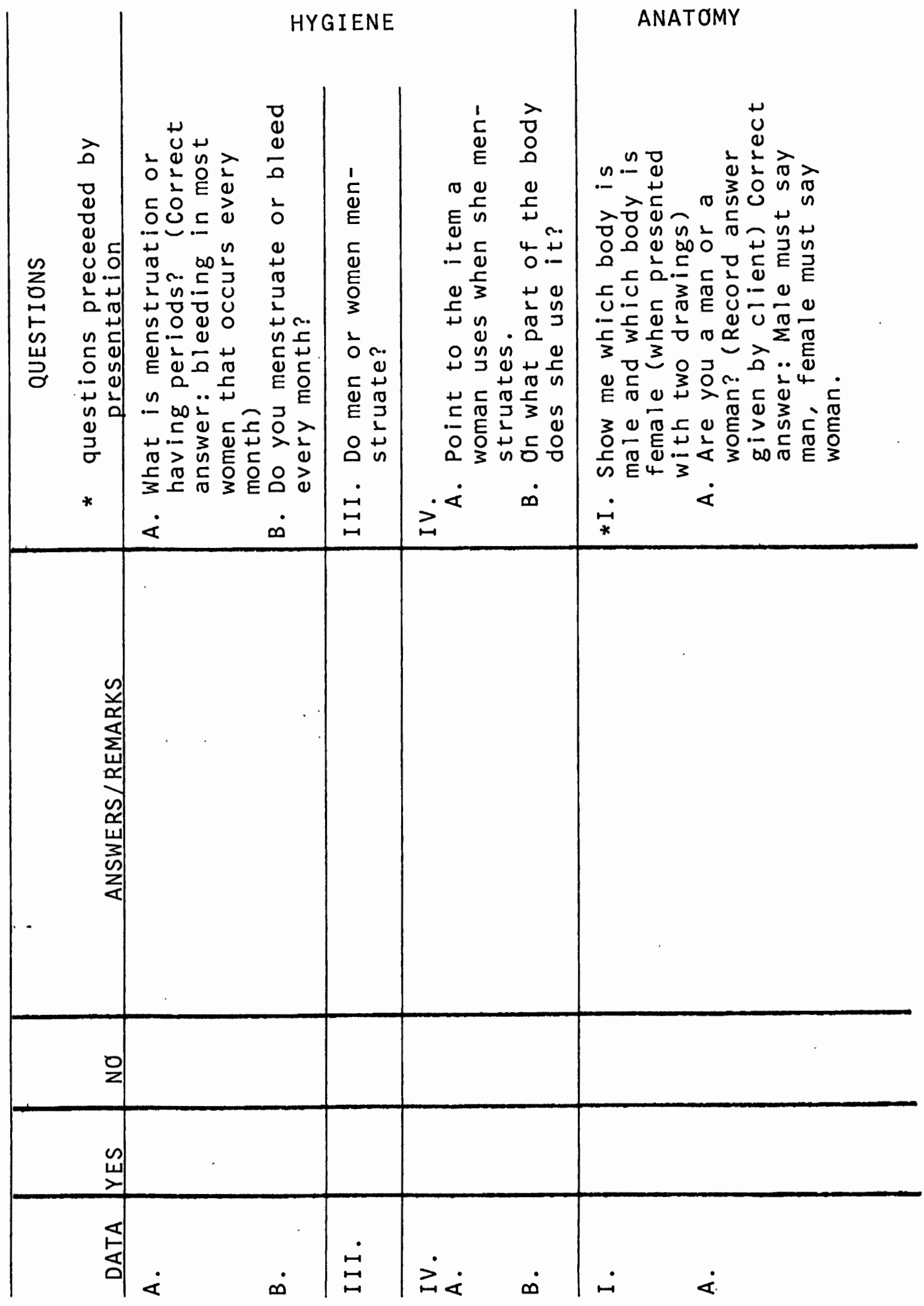




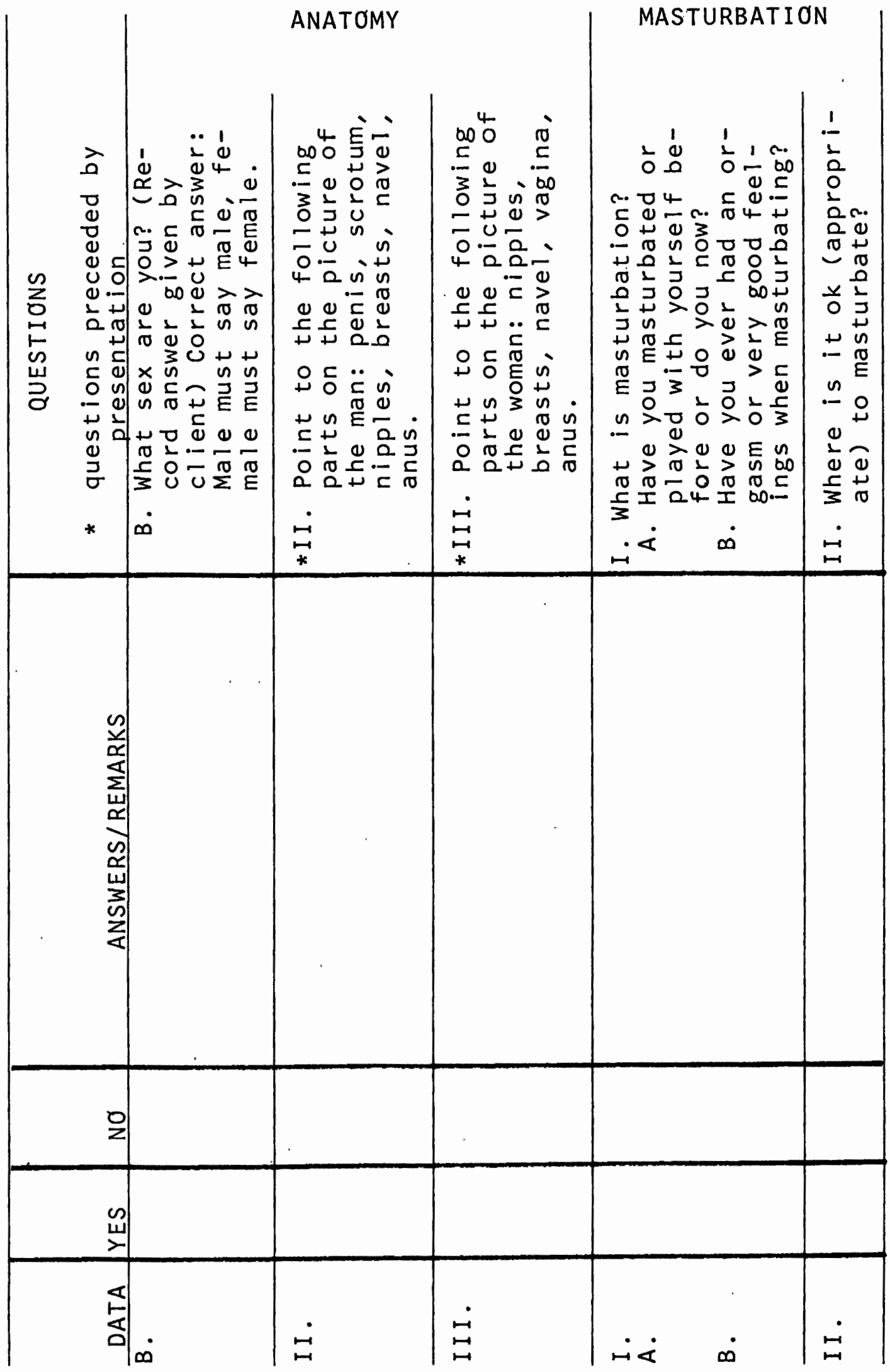




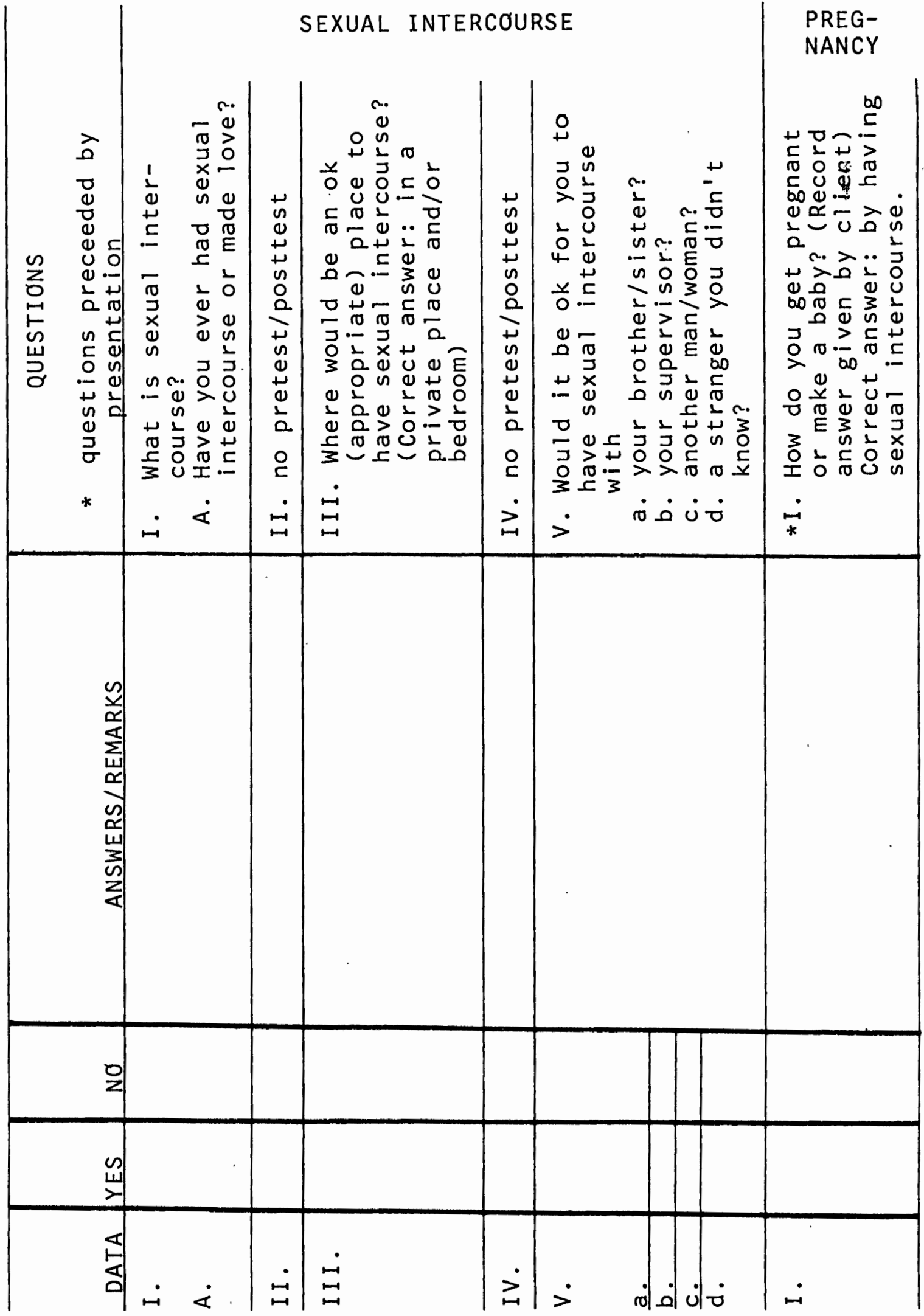




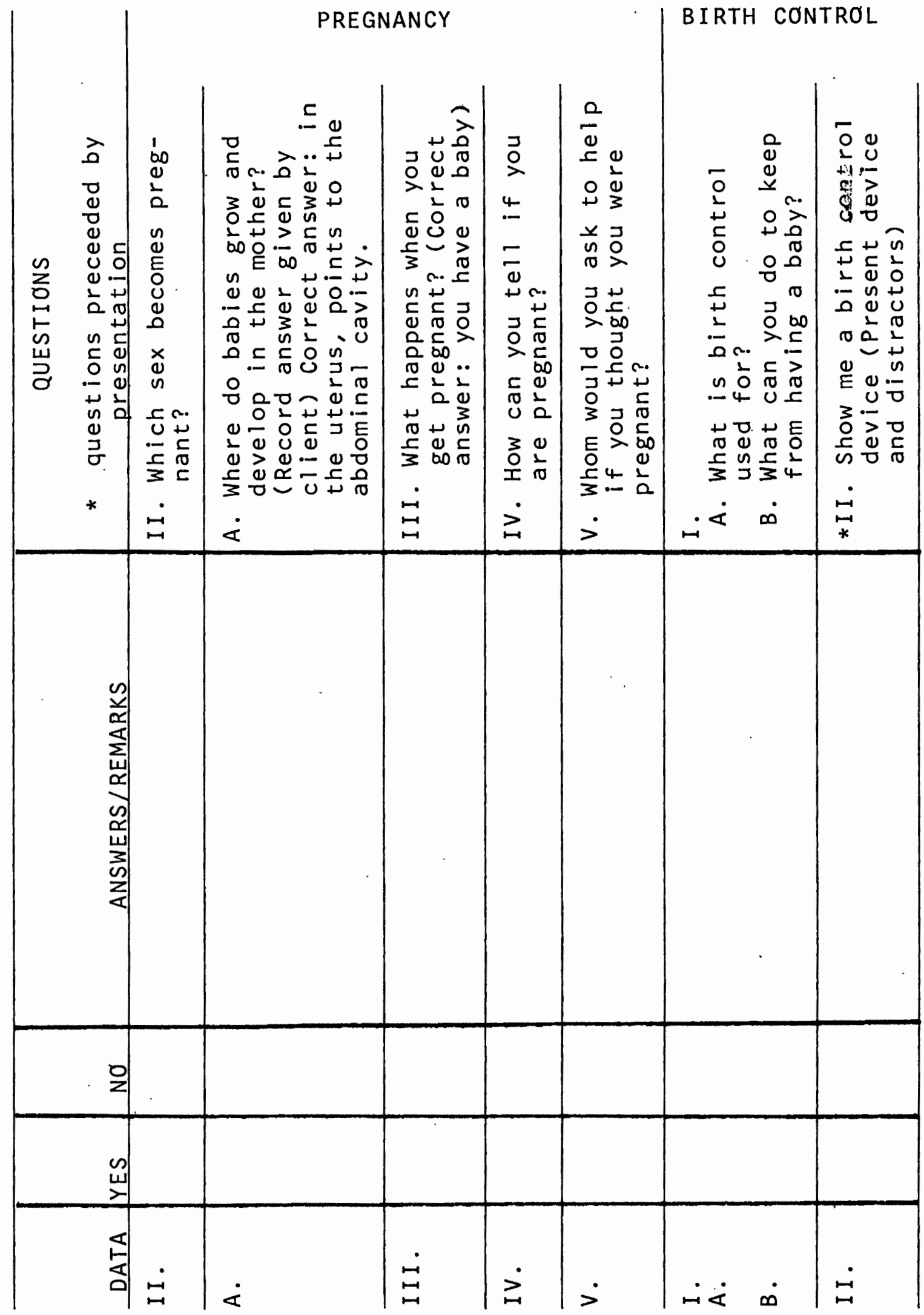




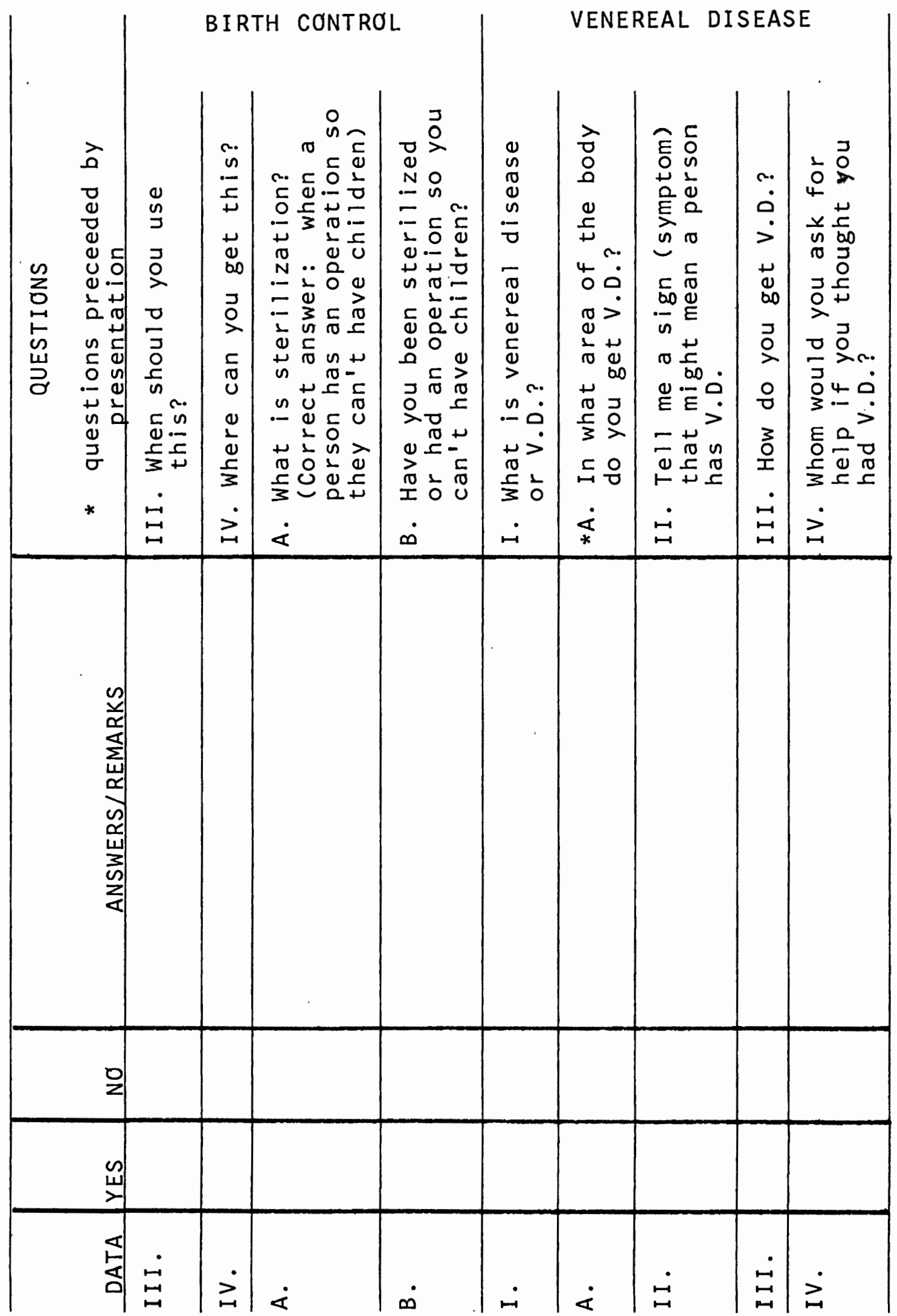




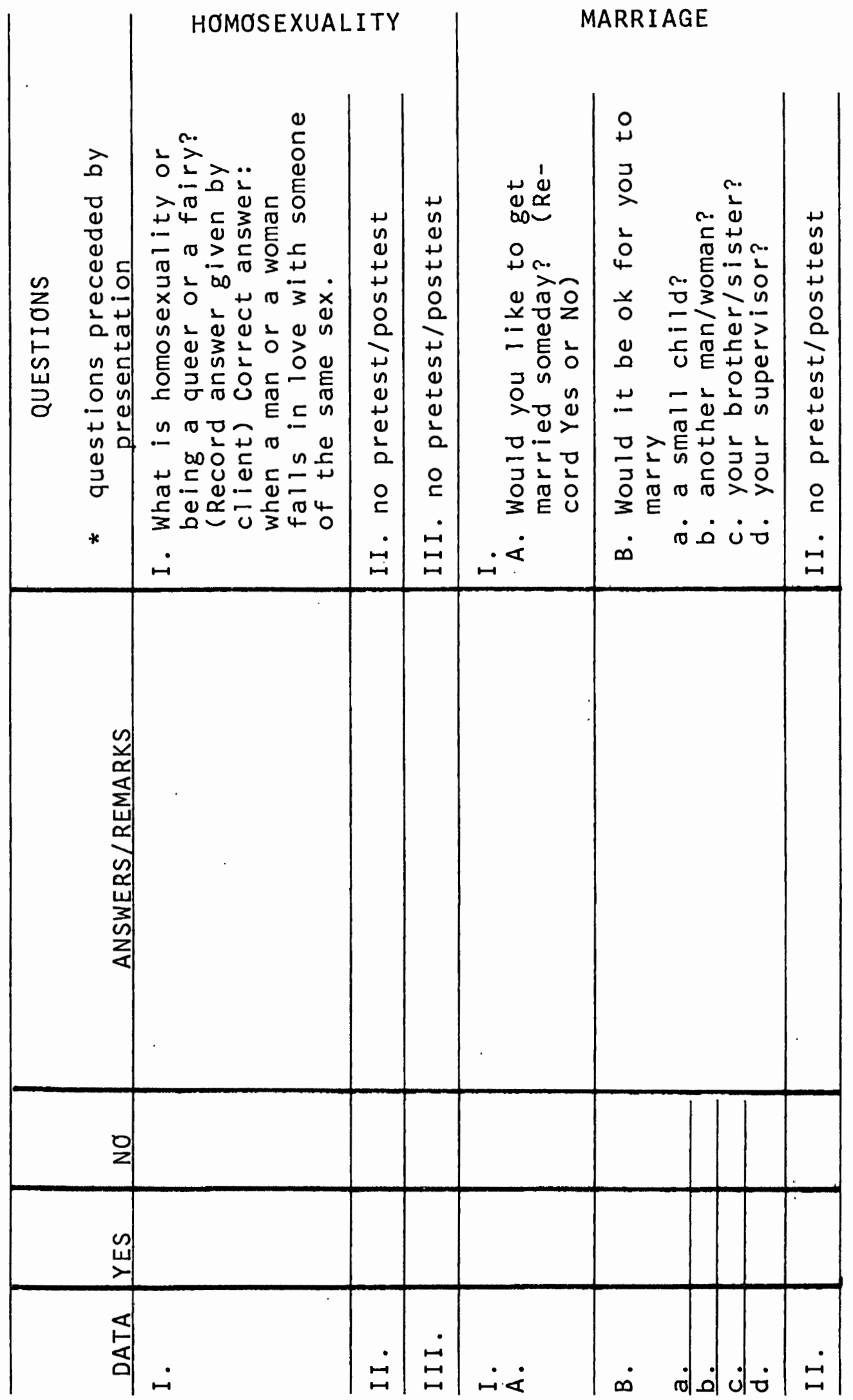




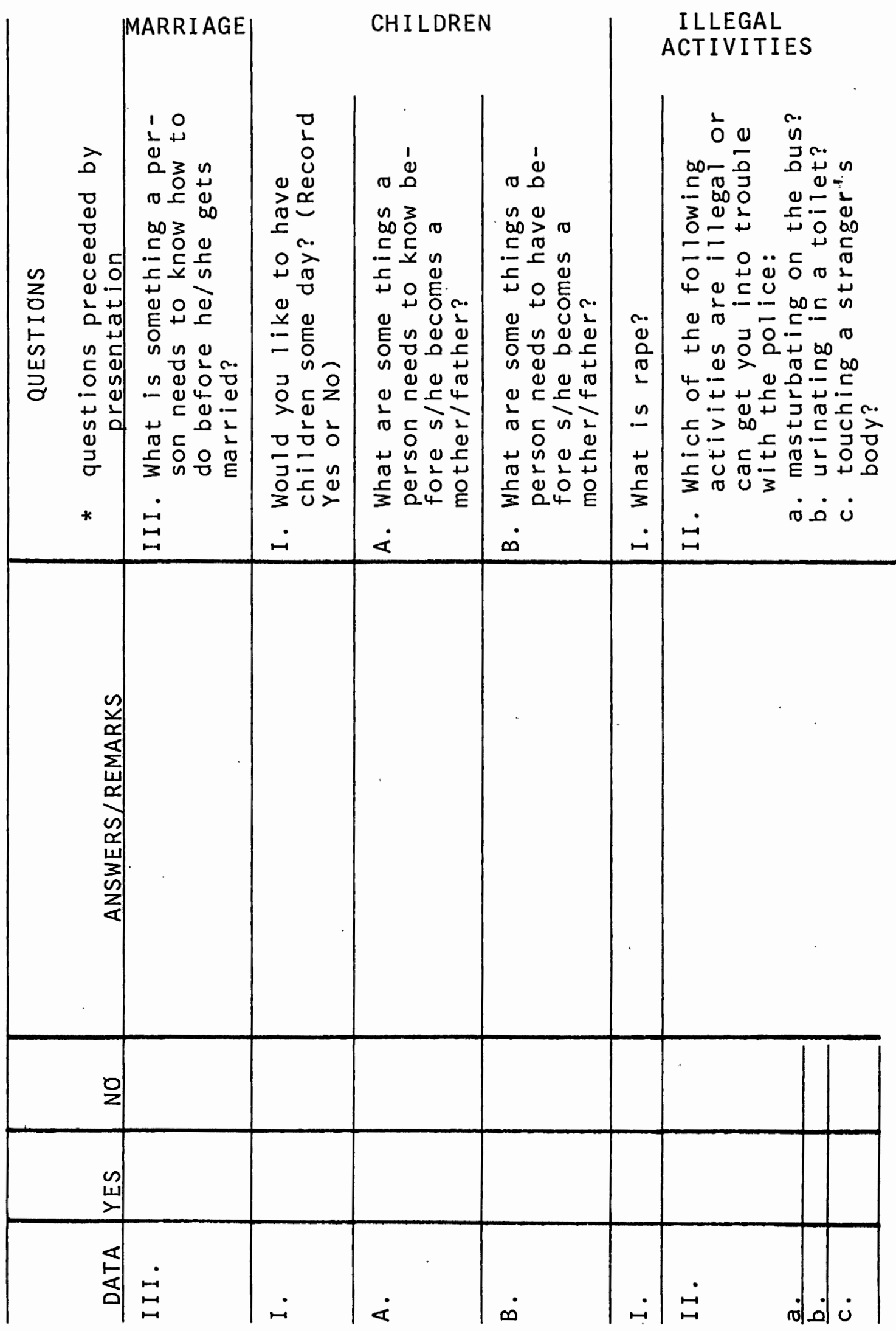




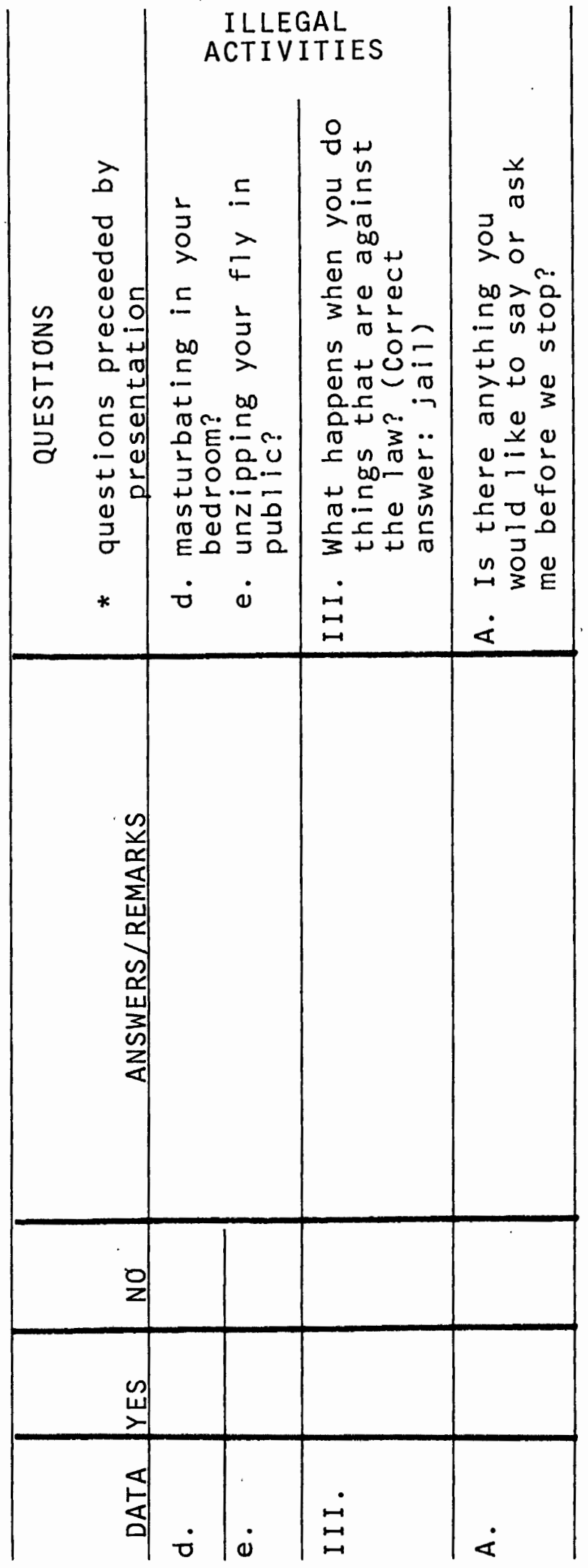




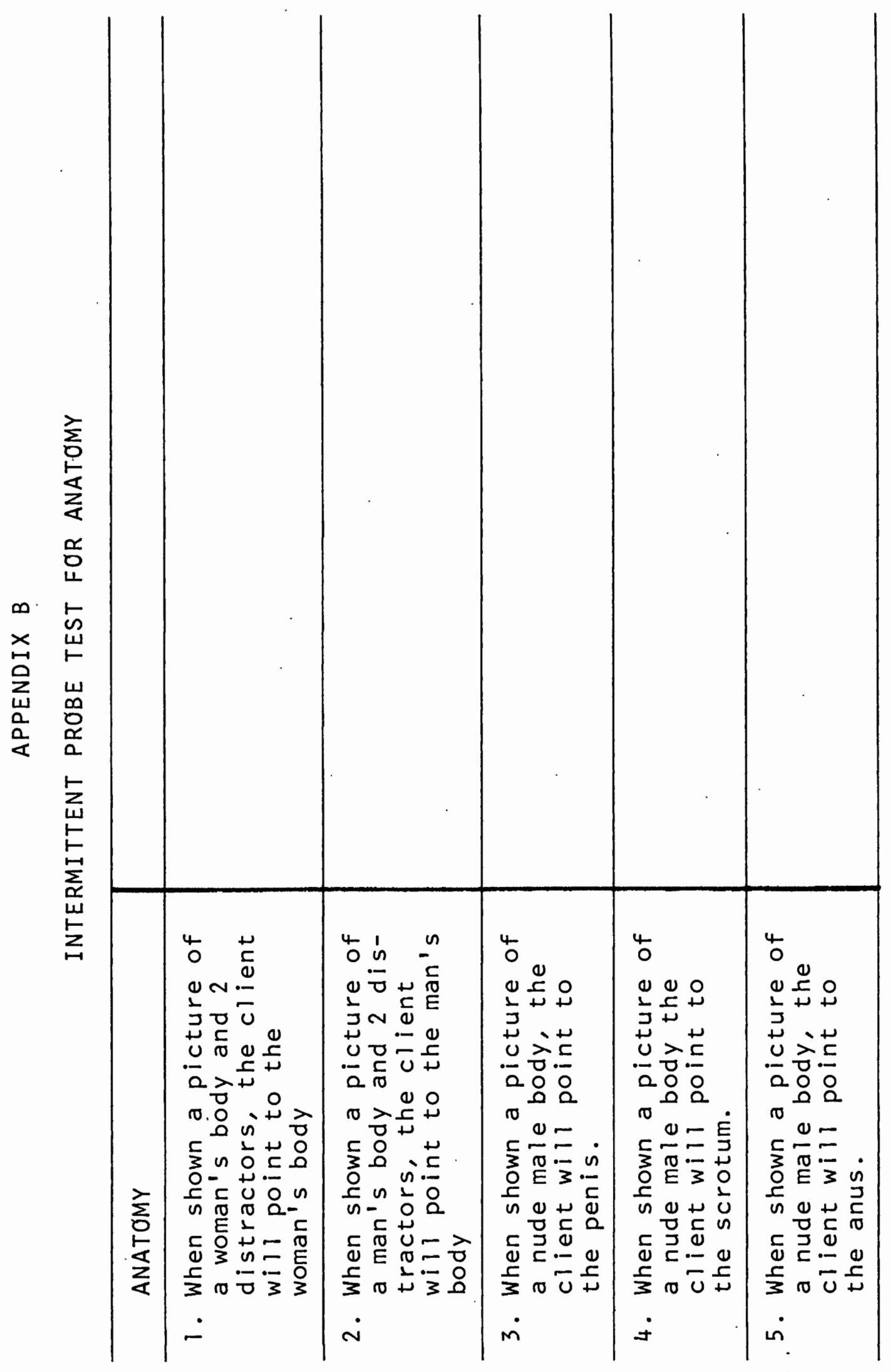


52

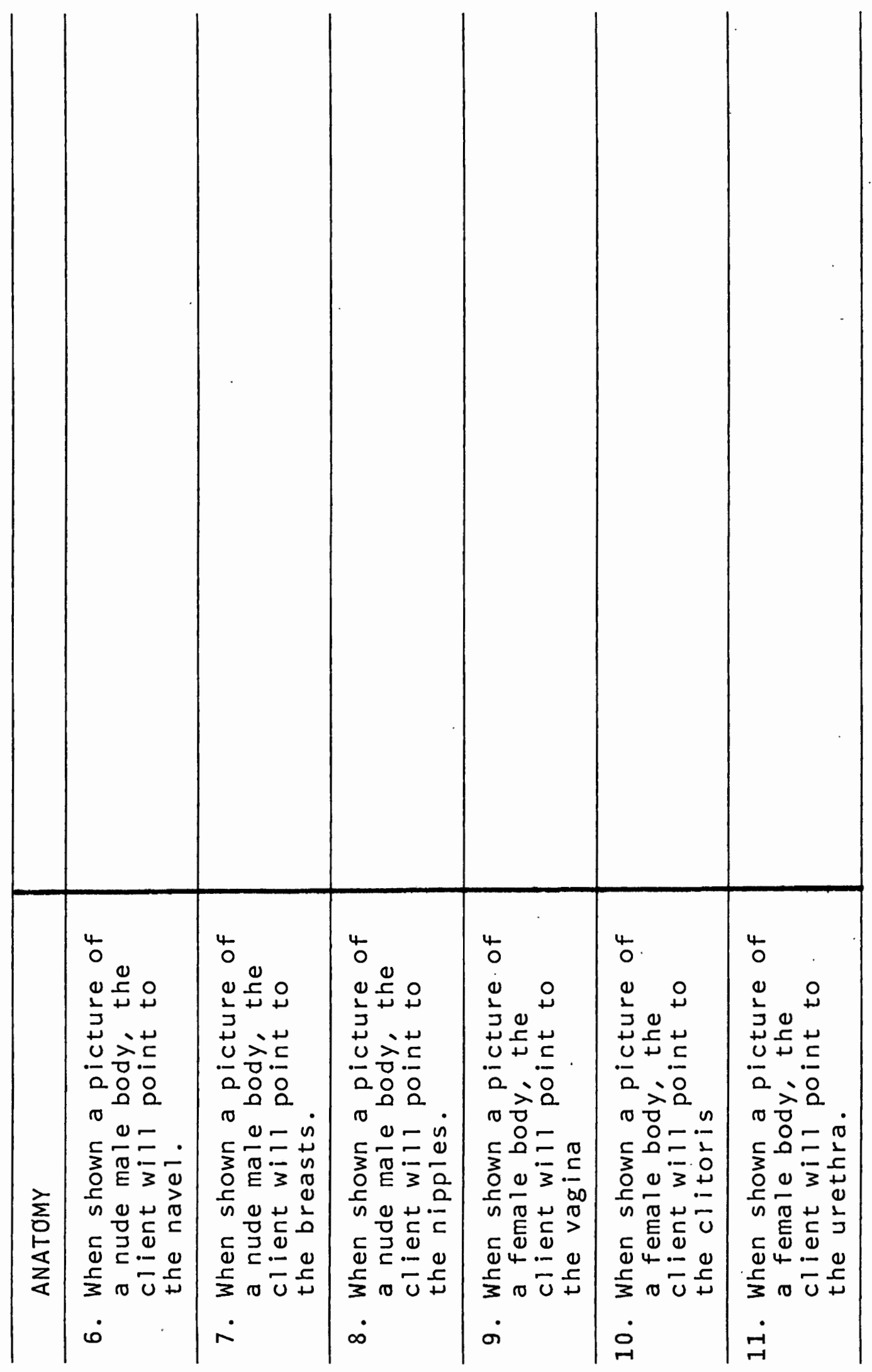




$$
\text { Ex: }
$$




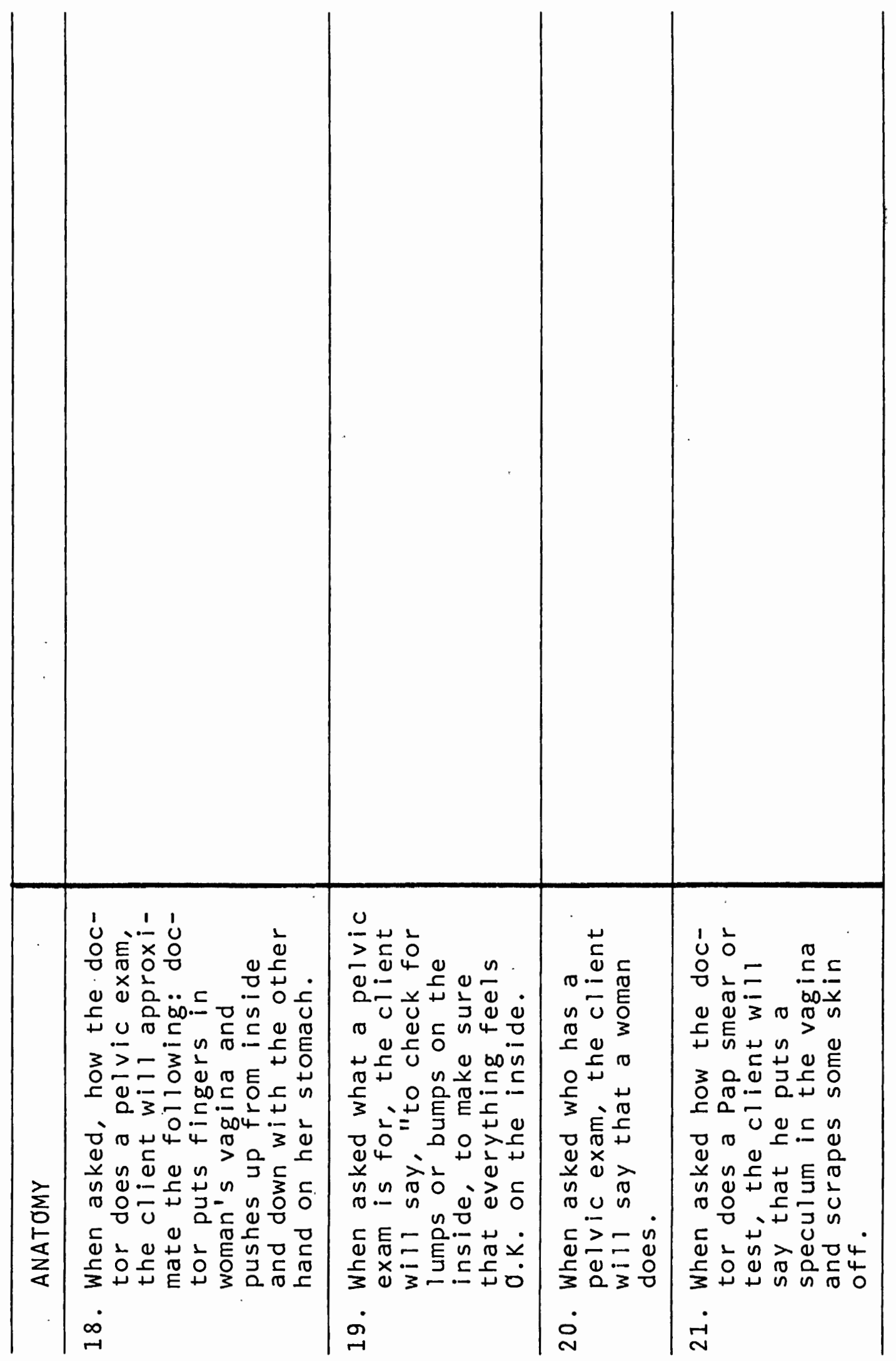




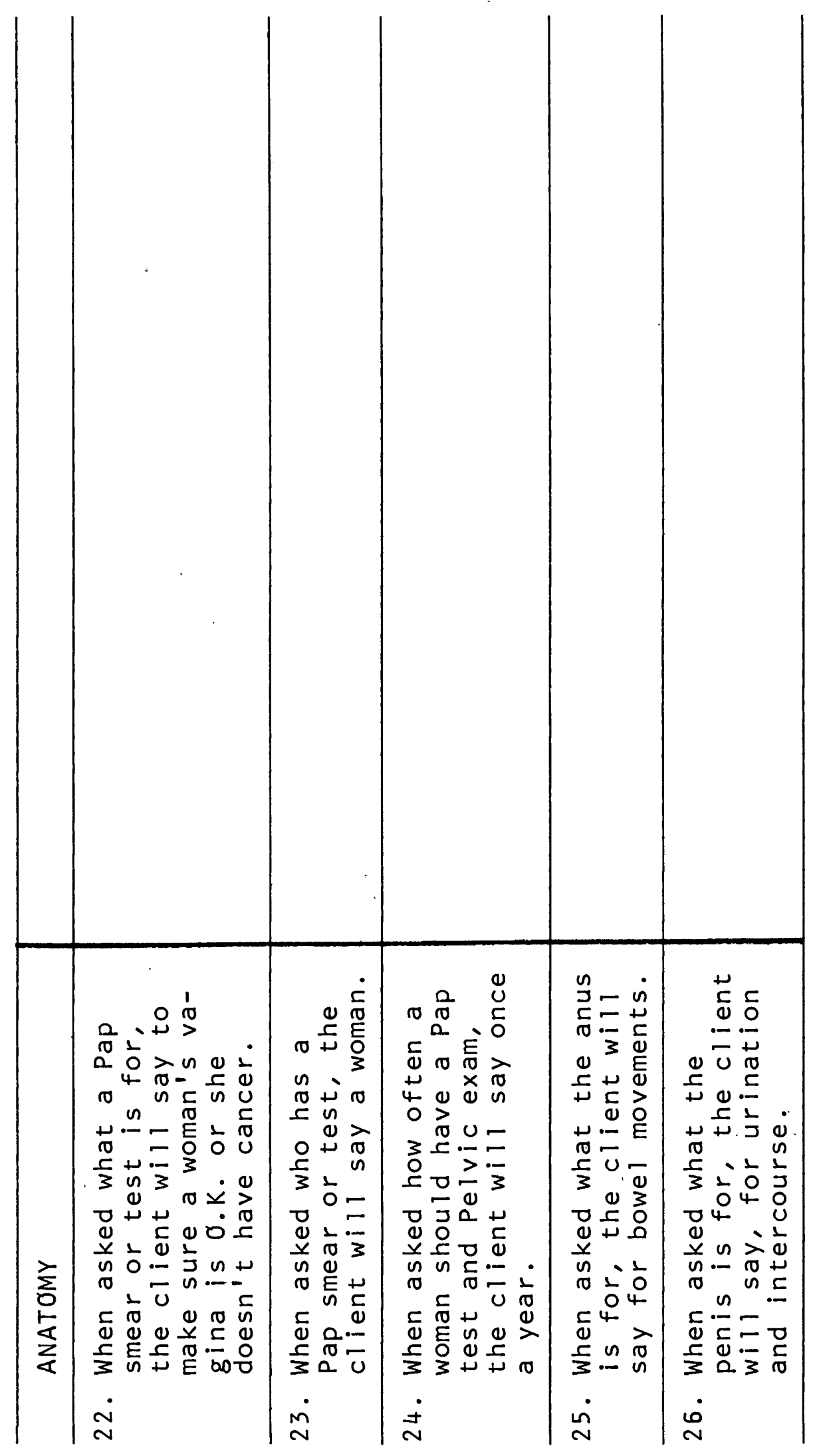




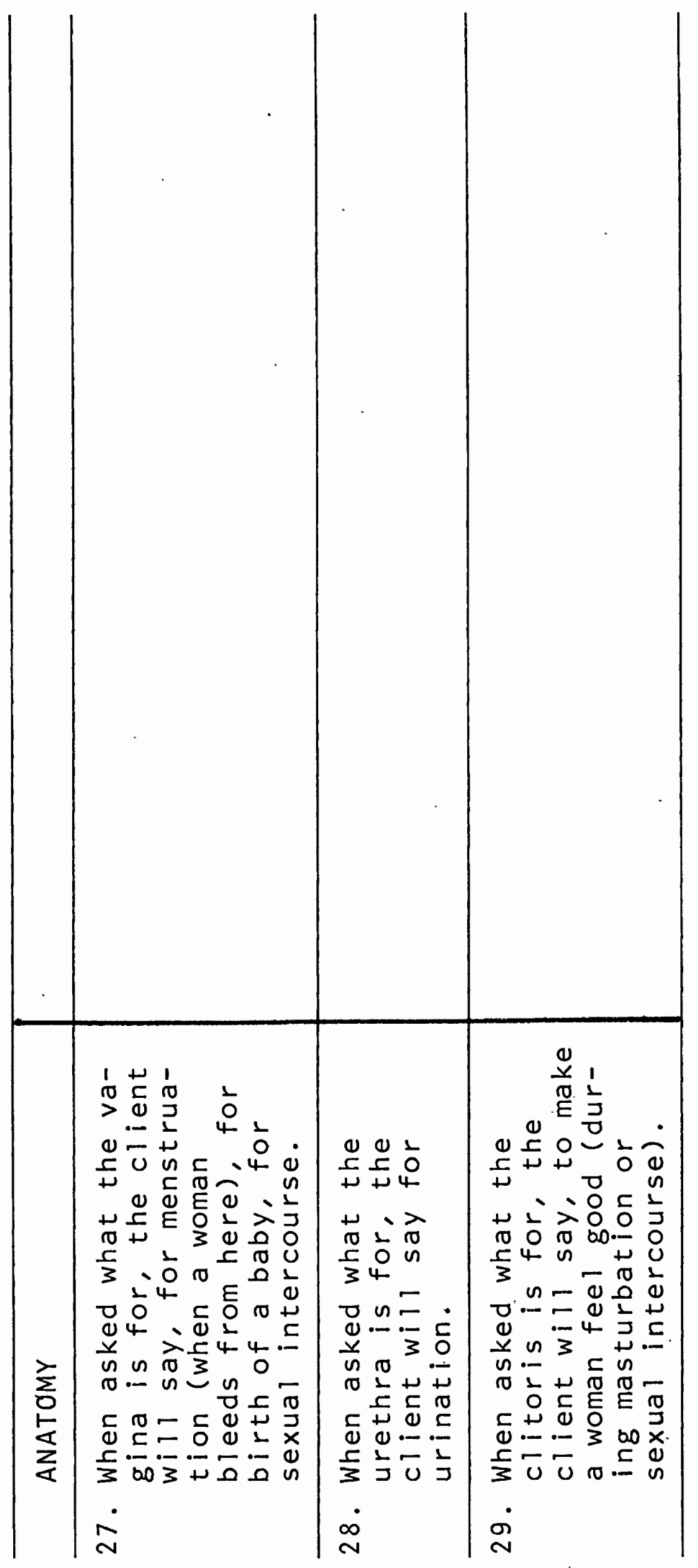


APPENDIX C

AGENCY FEEDBACK FORM

\section{CLIENT}

AGENCY

DATE

TOPIC AREA

MARRIAGE

OBJECTIVE

1. Given one correct choice and two distractors, the client chooses an appropriate marriage partner.

2. The client identifies 3 necessary preskills to marriage. "If a person is going to get married, do they need a. to be able to cook for themselves/yes

b. to be able to drive a car/no

c. to have a steady iob/yes

d. to be able to pay their own bills/yes

e. to be able to $\mathrm{read} / \mathrm{no}$

3. The client identifies one appropriate emotional relationship from two distractors. "Should a man and woman get married if they a. often hurt each others feelings/no

b. have done many things together for a long time/yes

c. just met/no

THE REMAINDER ARE OPTIONAL

4. The client defines marriage as: a legal and loving relationship between a man and a woman.

5. The client names two things that make marriage legal. License/blood test/person who marries you. 
6. The client identifies two characteristics of a "crush" relationship. - doesn't last long -don't trust each other - is basically sexual

7. The client identifies two characteristics of a "loving" relationship.

-a very close friendship.

- share work and fun.

-trust other person

- give more than receive

- feel the person is just as good as you. (approximations are o.k.)

COMMENTS (additional space on back of sheet) 
CLIENT

AGENCY

DATE

TOPIC AREA_ CHILDREN

1. The client says 2 things a married couple need to have before they have children. Acceptable: money, steady job, ability to meet health needs, education to 18 years, emotional needs, and a happy, secure home life.

2. The client discriminates between pictures those skills which a parent needs to be able to do from those they do not. $3+; 2-$

3. The client gives appropriate response to reasons for having children.

a. Your parents want grandchildren/no

b. Children can help you when you get older/no

c. Children can sometimes make you happy/yes

d. Many married couples have children/no

4. The client gives appropriate response to reasons for not having children.

a. You don't have enough money to take care of the child/yes

b. Your friend tells you all children are brats/no

c. Your sister/brother does not have children/no

d. You feel a child is too much responsibility/yes

COMMENTS (additional space on back of sheet) 
APPENDIX D

CLIENT REFERRAL FORM

\section{LANE COMMUNITY COLLEGE ABE SEX EDUCATION \\ REFERRAL FORM}

Client's name: first and last Referring agency

Client's social security no.

Client's street address

Client's birthdate

City, State, zip

Client's phone

******

1. Does the client live:

at home at a group home other (please describe)

2. Does the client participate in parks and recreation programs:

never occasionally often

if never; is that due to:

lack of interest or inappropriate social skills

3. Does the client have friends of both sexes? yes no

4. Does the client initiate social activities with:

friends: yes no alone: yes no 
5. Does the client have a current boyfriend or girlfriend? yes no

if yes, to the best of your knowledge has the relationship lasted:

1 month 6 months at least 1 year

6. In a public situation, does the client respond appropriately to meeting/interacting with: (if no, please describe)

-strangers

- friends/peers

-family

-staff

-boyfriend/girlfriend

7. Does the client independently perform necessary grooming and hygiene skills? (if no, please state specific skills which are not performed independently).

8. Is the client currently involved in any social behavior training within your agency which you would like to have continued in our classroom setting? (If so, please define and describe)

9. Is there any specific area or social-sexual skill which you feel the client needs counseling and/or tutoring? 
10. Is there any other information regarding this client which you feel would benefit us, as instructors, in meeting this client's individual social-sexual needs? (please describe) 